\title{
BROOD DIVISION AND THE ONTOGENY OF CACHING BEHAVIOUR IN THE NORTH ISLAND ROBIN (Petroica longipes)
}

BY

\section{LISABERTHA LATU TAMA CLARK}

\author{
A thesis \\ submitted to Victoria University of Wellington \\ in fulfilment of the requirements for the degree of \\ Master of Science in Ecology and Biodiversity
}

School of Biological Sciences

Faculty of Sciences

Victoria University of Wellington

2017 


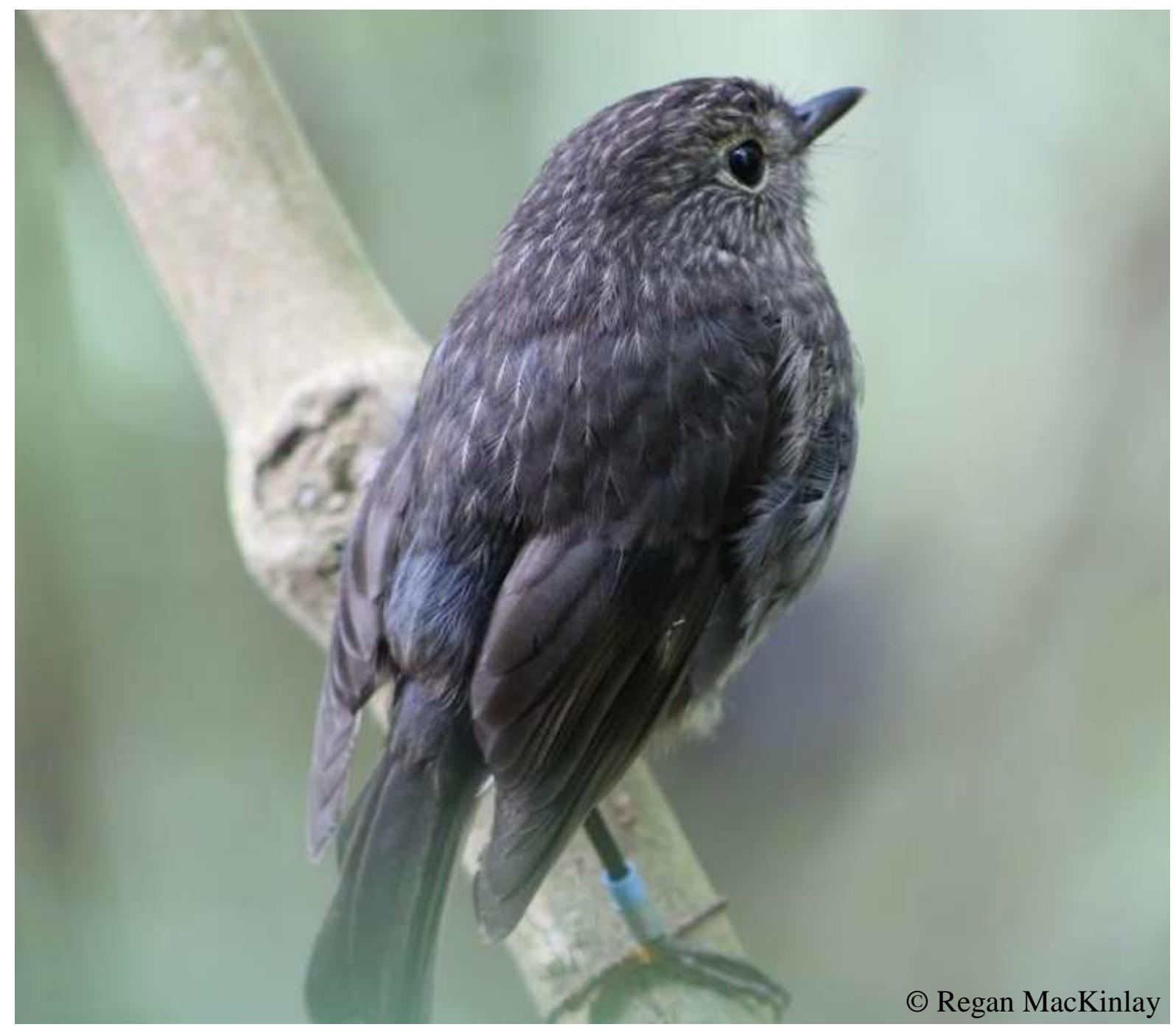

Supervisors:

A/Prof Kevin Burns

Senior Lecturer

School of Biological Sciences

Victoria University of Wellington
Dr Rachael Shaw

Post-Doctoral Fellow

School of Biological Sciences

Victoria University of Wellington 


\begin{abstract}
The post-fledging period is an important, but understudied, stage of avian development. This is despite the fact that the parental care and behavioural development of young observed during this period contribute significantly toward offspring survival. A key factor that has contributed to the lack of research in this area has been the difficulty with which parents and offspring can be observed during this period.
\end{abstract}

The North Island robin (Petroica longipes) is a small insectivorous passerine native to New Zealand forests. As a result of the historic absence of mammalian predators, North Island robins lack pronounced anti-predator behaviours and are fearless towards humans (Maloney \& McLean, 1995). This makes them ideal subjects for behavioural studies in the wild because human presence does not alter their daily activities.

Using field observations, the present study examined parental care and the development of caching during the post-fledging period in wild North Island robins. Brood division is a form of preferential post-fledging care that is well documented among avian species in the northern hemisphere. In contrast, little is known about the incidence and function of brood division in avian species outside this region. Across two breeding seasons (2014-2015 and 2015-2016), feeding interactions between parents and offspring were observed during nestling and fledgling development to determine the timing of and factors influencing brood division in robins. Brood division occurred around the time young left the nest and was common amongst broods which fledged two or more young. The male parent typically cared for male and larger fledglings and the female parent for female and smaller fledglings. The results of this study match patterns observed in northern hemisphere species suggesting that brood division provides the same adaptive advantages to species regardless of geographical context.

Caching, the handling of food to preserve it for future consumption, is an important strategy which allows numerous avian species to deal with natural fluctuations in food supply. In recent decades, caching has become a widely-used paradigm for examining a range of cognitive processes in birds, such as social cognition and spatial memory. However, much is still unknown about how caching develops in young birds, especially in the wild. Over a 12-week period following fledging, the ontogeny of caching and cache retrieval was observed for 34 
juvenile robins. Juveniles began caching shortly after achieving foraging independency (approximately 5 weeks after fledging) and their caching rates increased gradually with age. Retrieval of caches began spontaneously as soon as they had begun to cache and retrieval rates remained constant throughout development. Results suggest that caching behaviour in North Island robins is likely to be innate, but that age and experience have an important role in the development of adult caching behaviours.

The two studies described in this dissertation examine behaviours that have either been previously difficult to document in the wild or have not been documented in this species. Overall, the results highlight the behavioural similarities between the North Island robin and other avian species exhibiting brood division and caching. Additionally, they also demonstrate the suitability of the North Island robin for future behavioural research given the ease with which these birds can be observed in the wild. 


\section{Acknowledgements}

This research was supported by the Victoria University Masters by Thesis Scholarship and the Jim and Margaret Collins Grant.

Firstly, I would like to thank my supervisors A/Prof KC Burns and Dr Rachael Shaw for their incredible support of both my project and me. To Rachael especially: thank you for sitting with me on that terrible Monday afternoon when it felt like this thesis would never get completed. You've been one of my biggest supporters and a fantastic mentor for me over the past two years and I will be eternally grateful for all that you have taught me and for getting me over the finish line!

I would also like to thank Raewyn Empson and the Karori Wildlife Sanctuary Trust for permission to work at Zealandia Wildlife Sanctuary. I would like to especially thank Matu Booth and the Conservation Rangers for their willingness to assist in me in the field or answer my queries over the radio. Furthermore, I would like to acknowledge Annette Harvey for her incredible robin knowledge and her work banding the juveniles in this study. I'd also like to thank Jo Hawthorne for her companionship in the field and for her assistance coding videos.

I also wish to acknowledge the support of Te Rōpū Āwhina. My deepest thanks to Liz Richardson - your belief in my potential set me upon this research journey 3 years ago and in that time I've met so many incredible people and have had so many fantastic opportunities. Malo 'aupito!

Thank you to the Bird Nerds - Ellen Irwin, Regan MacKinlay, Johannes Fischer, Daniel Donoghue, Chris Woolley and Bart Cox. You've been an incredible support system throughout this thesis and I will surely miss your companionship and bird chat. A special thank you to Regan for allowing me to use one of your photographs as the frontispiece and for your tireless assistance in the field.

I would also like to thank my family and friends for coming along with me on this journey. Toward the end, you had to put up with an increasingly stressed, emotional and absent friend and daughter. I cannot thank you enough for allowing me to be each one of those things and 
for constantly showering me with your love and encouragement. To all the amazing women in my life - Mum, Lena, Daisy, Aunty Meg, Aunty Vai, Nena Latu - this thesis is dedicated to you.

Finally, I would like to acknowledge the wonderful birds that made this thesis possible. My time in the forest with you has been an incredible learning experience, one that I believe goes beyond the pages of this thesis as demonstrated beautifully by this whakatauki (Maori proverb):

Ko te manu e kai i te miro nōna te ngahere, Ko te manu kai i te mātauranga, nōna te ao.

The bird that eats the miro berry owns the forest. The bird that feasts on knowledge owns the world. 


\section{Table of Contents}

Abstract

Chapter 1: General Introduction ..........................................................................

Chapter 2: Parental Care and Brood Division in the North Island robin (Petroica

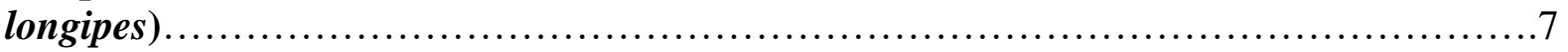

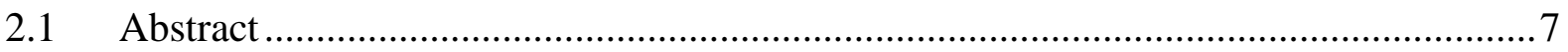

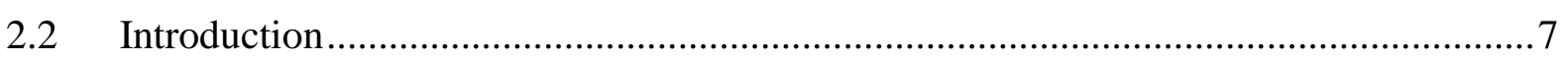

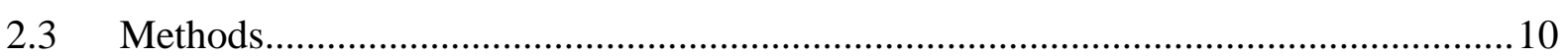

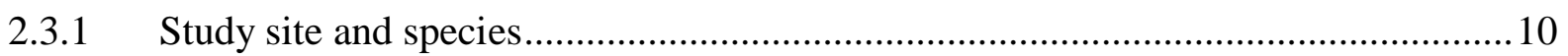

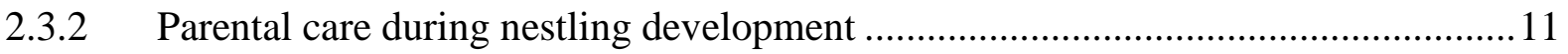

2.3.3 Post-fledging care and brood division................................................................. 12

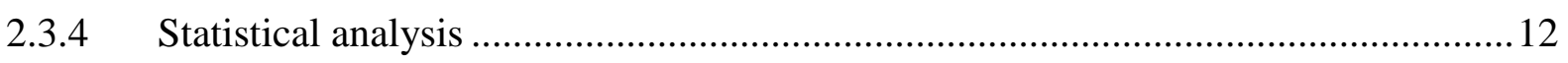

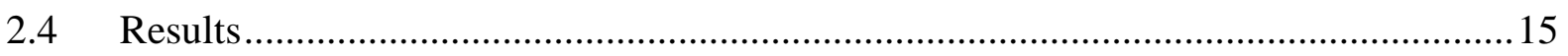

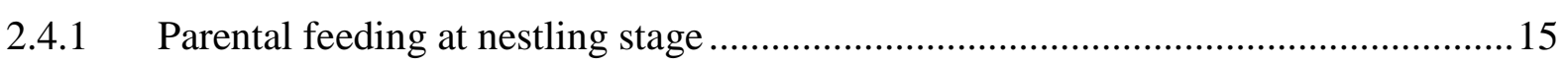

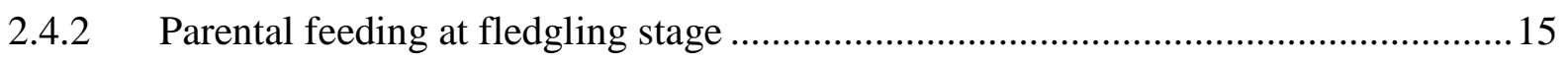

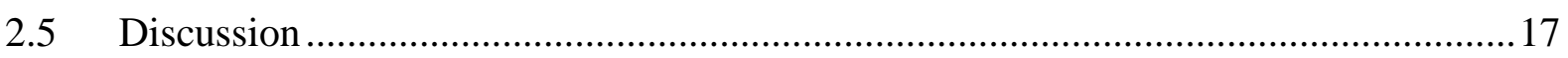

Chapter 3: The Ontogeny of Food-Caching Behaviour in North Island robins (Petroica

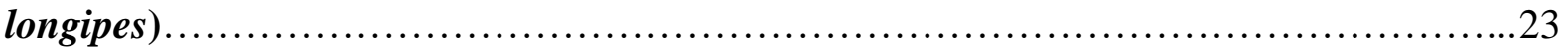

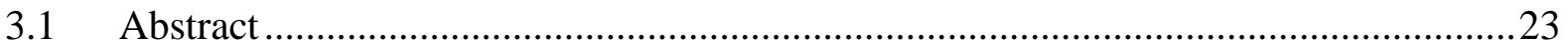

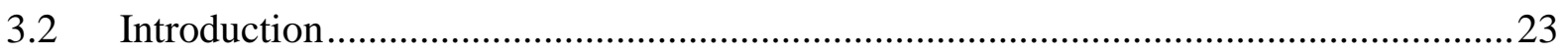

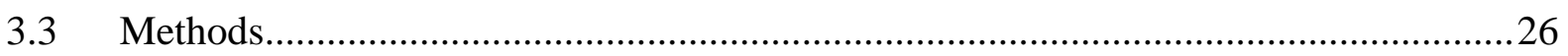

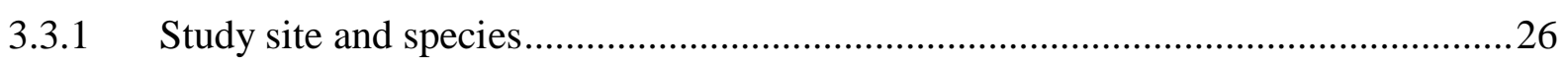

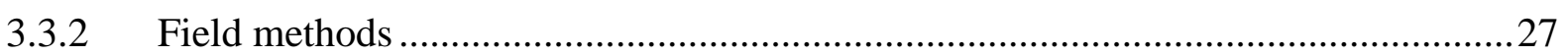

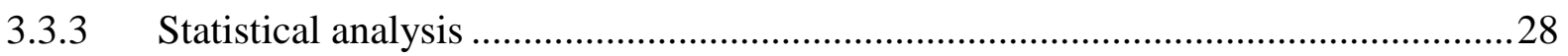

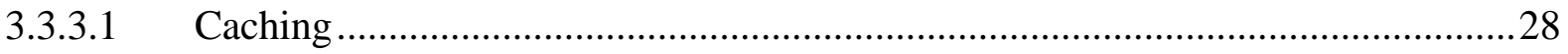

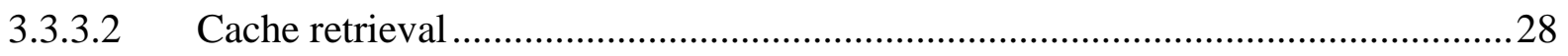




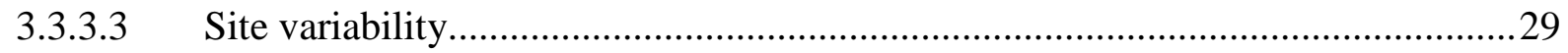

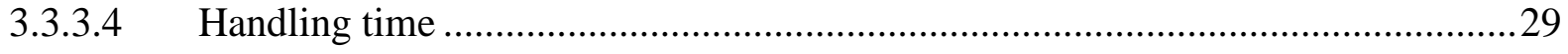

3.3.3.5 Comparing juvenile and adult caching behaviour ............................................29

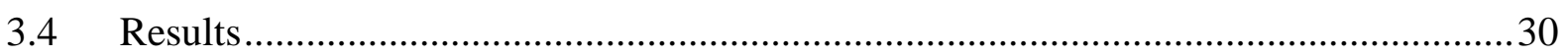

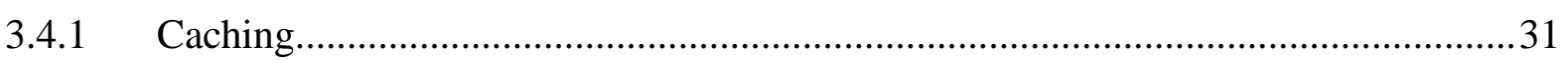

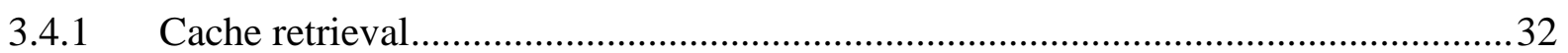

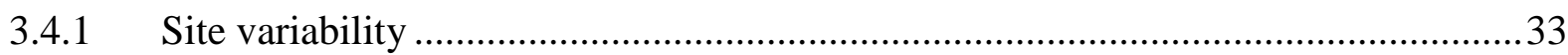

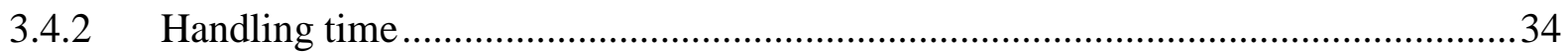

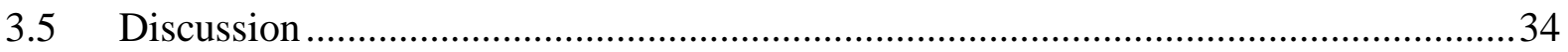

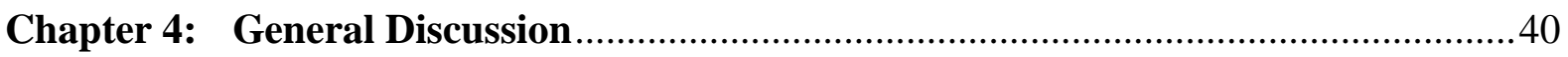

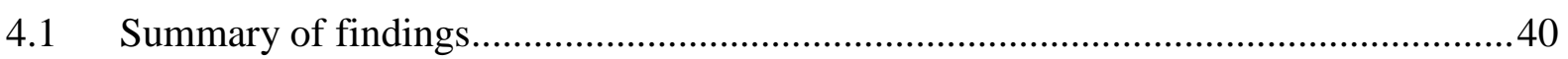

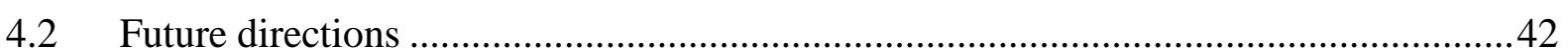

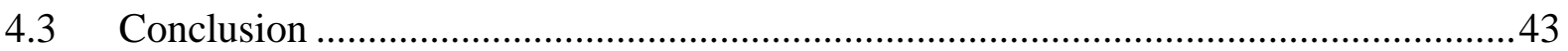

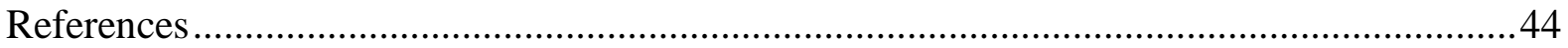

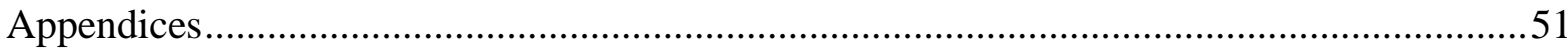




\section{List of Figures}

Figure 1. Ratio of male to female caregivers at brood division for four offspring types: malelarge (M-L), male-small (M-S), female-large (F-L) and female-small (F-S) ................17

Figure 2. Examples of sites used by juvenile robins to cache mealworms

Figure 3. Mean proportion of mealworms cached (A) and retrieved (B) as a function of juvenile age (weeks since fledging) .32

Figure 4. Mean site variability (the number of cache sites used) as a function of fledgling age (weeks since fledging)....

Figure 5. Mean handling time as a function of fledgling age (weeks since fledging). .34 


\section{List of Tables}

Table 1. Model generated from GLMM (binomial distribution with a logit link function) which examines the effect of offspring sex and size on caregiver sex following brood

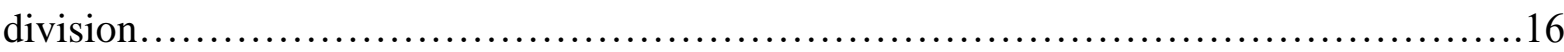




\section{List of Appendices}

Appendix 1 Distribution of parental feeds to single-fledgling broods....................51

Appendix 2 Distribution of parental feeds among broods of two or more fledglings........52

Appendix 3 Description of behaviours seen during observations of juveniles during the post-

fledging period. .54

Appendix 4 GLMM model (Binomial distribution with logit function) investigating the factors affecting the proportion of mealworms cached by juvenile robins

Appendix 5 GLMM model (Binomial distribution with logit function) of the factors affecting the proportion of cached mealworms retrieved by juveniles.

Appendix 6 GLMM model (Poisson distribution with log function) of terms proposed to affect number of sites used by fledglings when caching .55

Appendix 7 LMM model (Gaussian distribution) of the factors affecting the handling time of cached items.... .55 


\section{Permits}

All methods were approved by the Victoria University of Wellington Animal Ethics Committee and conducted under permit from the Department of Conservation (Authorisation number: 38497-FAU). 


\section{Chapter 1: General Introduction}

For many birds, the post-fledging period (i.e. the time between young leaving the nest and natal dispersal) remains an understudied life stage (Aroyo, De Cornulier, \& Bretagnolle, 2002; Cox, Thompson, Cox, \& Faaborg, 2014; Ridley \& Raihani, 2007; Smith, 1978; Weatherhead \& McRae, 1990). This is despite the fact that the parental care and behavioural development of offspring observed during this period contribute significantly toward offspring survival (Clutton-Brock, 1991; Cox et al., 2014; Green \& Cockburn, 2001; Heinsohn, 1991; Langen, 2000). Studying the post-fledging period in wild birds is therefore, an invaluable opportunity to better understand the factors affecting offspring survival.

Parental care refers to any behaviour exhibited by parents, which increases the fitness of their young (Clutton-Brock, 1991). Behaviours of this description include nest building or burrowing, egg brooding, nest defence and food provisioning (Royle, Smiseth, \& Kolliker, 2012). Among avian species, biparental care is a widespread strategy occurring in approximately $75 \%$ of known species (Cockburn, 2006). It is especially common among altricial species whose young are naked, blind and helpless following hatching and subsequently, are totally reliant upon parental feeding and care (Cockburn, 2006). By providing care to young, parents increase offspring survival and their own reproductive fitness (CluttonBrock, 1991; Royle et al., 2012). However, there are also significant costs to providing parental care because such investments redirect time and resources away from other processes (e.g. selfmaintenance) or other offspring (current or future) (Clutton-Brock, 1991; Royle et al., 2012).

Parental investment theory predicts that parents should adjust their level of care in relation to the value of offspring (Trivers, 1972). This is because for many species, males and females differ in their reproductive constraints, e.g. gamete production; as such, the compromises that they make between parental care and other activities may differ significantly in their consequences (Bateman, 1948; Trivers, 1972). Thus, even within birds with biparental care, where both sexes cooperatively care for young, each parent may show differential care toward particular offspring (reviewed in Lessells, 2002). Previous studies have demonstrated that offspring of different ages, sizes and sexes can be differentially cared for by male and female parents (Budden \& Beissinger, 2009; Byle, 1990; Gowaty \& Droge, 1991; Harper, 1985; McLaughlin \& Montgomerie, 1985; Shiao, Chuang, \& Wang, 2009; Tanner, Kölliker, \& 
Richner, 2008; Vega, Holloway, Millett, \& Richardson, 2007; Wheelwright, Tice, \& FreemanGallant, 2003). For example, in Common Murres (Uria aalge), fathers tend to provide a larger feeding investment to male offspring in comparison to female offspring (Cameron-MacMillan, Walsh, Wilhelm, \& Storey, 2007). Additionally, other studies have found that young of different sizes are not equally provisioned by male and female parents. Typically, the smallest offspring are fed primarily by female parents and the largest by male parents (Linkhart \& Reynolds, 1987; Slagsvold, Amundsen, \& Dale, 1994). Given how vital parental care is to the young of numerous avian species, identifying what factors influence care decisions is an important step to understanding offspring survival in the wild.

The post-fledging period is an important stage of development for many birds. Following their departure from the nest and prior to natal dispersal, many species are reliant upon parents for some or all of their nutritional needs (Cox et al., 2014). Parental care during this period has been shown to offer young considerable advantages, such as increased probability of overwinter survival and a higher body mass at nutritional independence (Langen, 2000). Additionally, it is during this period that young learn and develop important skills, such as foraging and flight, that will aid in their survival post-independency (Bustamante, 1993; Guo, Cao, Peng, Zhao, \& Tang, 2010). Yet despite being an influential factor in the development and survival of young, the post-fledging period remains a relatively understudied life stage. This is due to the difficulty with which parents and offspring can be monitored once offspring have fledged (Aroyo et al., 2002; Langen, 2000; Ridley \& Raihani, 2007; Smith, 1978; Weatherhead \& McRae, 1990).

Brood division is a form of preferential care that is common at the fledgling stage. Brood division describes the division of offspring care between parents, such that each parent cares only for a specific subset of offspring (Leedman \& Magrath, 2003; McLaughlin \& Montgomerie, 1985; Slagsvold, 1997; Smith, 1978). Broods may be divided between parents based on offspring sex or size, or randomly (reviewed in Lessells, 2002; Vega et al., 2007). A range of hypotheses have been proposed to explain the function of brood division in birds (Slagsvold, 1997; Tarwater \& Brawn, 2008; Wheelwright et al., 2003). However, broad generalisations about the function of brood division have been difficult to make, largely due to the variability with which it is expressed within individuals and populations (Tarwater \& Brawn, 2008). Additionally, most studies have been conducted with species endemic to the northern hemisphere; consequently, less is known about the incidence and function of brood 
division in avian species outside this region. Brood division establishes specific parental care environments for young following fledging and thus, could have important implications for other developmental processes during this time.

The post-fledging period is also a time of significant behavioural development in young birds. During this time, fledglings are reliant upon parents for some or all of their nutritional requirements but they become increasingly independent as foraging skills develop (Heinsohn, 1991; Kross \& Nelson, 2012; Wheelwright \& Templeton, 2003). Foraging skills are necessary for independent survival following natal dispersal however, few quantitative studies have examined how and when foraging skills develop in young, wild birds (Guo et al., 2010; Weathers \& Sullivan, 1989, 1991; Wheelwright \& Templeton, 2003). This relates to the difficultly with which fledglings can be monitored once they are capable of flying (Langen, 2000; Smith, 1978; Weatherhead \& McRae, 1990). Additionally, there have been even fewer studies conducted of more specialised forms of foraging, such as food hoarding or caching (Vander Wall, 1990).

Caching behaviour represents the unique ability of some birds to store excess food in their environment thereby, preserving it for future consumption (Vander Wall, 1990). Generally speaking, there are two patterns of cache distribution: scatter hoarding and larder hoarding (Vander Wall, 1990). The former describes the wide distribution of food items to many different locations (typically one item per site); conversely, the latter describes the clumped distribution of food usually at a single site (Brodin, 2010). Food may be stored on a long-term (i.e. weeks or months) or short-term (i.e. hours or days) basis depending on the perishability of the item and the function of the cache (i.e. competition or preparation) (Vander Wall, 1990). Caching has evolved in a wide-range of avian taxa and is common among species of the Corvidae and Paridae families (Vander Wall, 1990).

Daily, seasonal or random fluctuations in the availability of food are common in natural environments. Some animals take advantage of temporary abundances by storing excess food internally as fat; however, such a strategy is unsuitable for most birds as excess weight could impact flight and accordingly, increase their risk of predation (Witter, 1993). In the last decade, caching has become a common paradigm for examining a range of cognitive processes, such as social cognition and spatial memory in birds (Thomas Bugnyar, Stöwe, \& Heinrich, 2007; Clayton, 1992, 1994; Salwiczek, Emery, Schlinger, \& Clayton, 2009). However, despite the 
prevalence with which it has been studied by comparative cognition researches, there remains only a few detailed ontogenetic studies of caching (Vander Wall, 1990). Even fewer still, are the studies that have been conducted in the wild (Haftorn, 1992; Stotz \& Balda, 1995). Thus, there are significant gaps in our understanding of how and when this behaviour develops in natural environments. These are necessary to address if we are to gain a greater understanding of the mechanisms that shape this behaviour and how caching contributes to survival in the wild.

The study of brood division and caching in the wild during the post-fledging period has typically been hindered by the mobility of young birds and the wariness of both parents and offspring toward humans (Aroyo et al., 2002; Cox et al., 2014; Smith, 1978). Like many birds endemic to isolated islands, North Island robins (Petroica longipes) are extremely 'naïve' and lack pronounced anti-predatory behaviours (sensu Carlquist, 1970). Consequently, robins are unperturbed by and will readily approach human observers making them an ideal species for studies of parental care and behavioural ontogeny in the wild.

The North Island robin is a small, insectivorous passerine native to forest and scrub habitats of New Zealand (Higgins \& Peter, 2002). Like many songbirds, robins typically form life-long pair bonds and both sexes contribute to the care of nestlings (Armstrong et al., 2000). However, upon fledging broods are typically divided between parents and fledglings are fed for 25 to 50 days before dispersing from the natal territory (Armstrong et al., 2000; Heather \& Robertson, 2005; Powlesland, Knegtmans, \& Marshall, 2000). North Island robins are also one of a few species in the southern hemisphere which caches food (Vander Wall, 1990). Their diet includes some of the world's largest invertebrates such as giant earthworms (Lumbricidae), which are dismembered and pieces not immediately eaten, are cached for future consumption (Alexander et al., 2005; Powlesland, 1980). Adult caching behaviour has been well studied in this species but as yet, there have been no studies of the development of caching in young robins (Alexander et al., 2005; Burns, 2009; Burns \& Steer, 2006; Burns \& Van Horik, 2007; Van Horik \& Burns, 2007).

The objective of this study was to examine post-fledging parental care and the ontogeny of caching behaviour in wild North Island robins. In Chapter 2, I present a detailed examination of brood division in robins and discuss my results in the context of the most common hypotheses proposed to explain brood division in birds. In Chapter 3, I describe the ontogeny 
of food-caching behaviour in juvenile robins and discuss my results considering other ontogenetic studies in caching birds. In Chapter 4, I summarise the results of two preceding chapters, comment on their shared significance to our understanding of the post-fledging period and suggest areas for future research. 


\title{
Chapter 2: Parental Care and Brood Division in the North Island robin (Petroica longipes)
}

\begin{abstract}
2.1 Abstract
Brood division, in which the care of offspring is divided between parents, has been well documented in birds. However, most studies have observed the behaviour in species endemic to the northern hemisphere, thus there remains gaps in our knowledge with regard to how this behaviour might be expressed in avian species outside this region. The division of offspring care in this way is thought to not only reduce predation risk, but also to offer opportunities for the transmission of sex-specific behaviours from adults to young. The present study examined the timing and factors influencing brood division in a wild New Zealand passerine, the North Island robin (Petroica longipes). Across two breeding seasons (2014-2015 and 2015-2016), feeding interactions between parents and offspring were observed during nestling and fledgling development. Brood division occurred around the time young left the nest and was common amongst broods which fledged two or more young. The male parent typically cared for male and larger fledglings and the female parent for female and smaller fledglings. The results of this study match patterns observed in northern hemisphere species suggesting that brood division provides the same adaptive advantages to species regardless of geographical context.
\end{abstract}

\subsection{Introduction}

Biparental care is prevalent amongst the majority of bird species prior to offspring leaving the nest (Clutton-Brock, 1991). However, numerous observations of post-fledging care have suggested that parents typically divide broods and care between them during this developmental period (Anthonisen, Krokene, \& Lifjeld, 1997; Byle, 1990; Davison, 1992; Leedman \& Magrath, 2003; Linkhart \& Reynolds, 1987; McLaughlin \& Montgomerie, 1985; Slagsvold, 1997; Tarwater \& Brawn, 2008; Vega et al., 2007; Weatherhead \& McRae, 1990). Brood division occurs when broods are physically divided and one or both parents preferentially care for a subset of the fledglings in a brood in separate areas of a shared breeding territory (McLaughlin \& Montgomerie, 1985; Slagsvold, 1997). Where brood division has been formally studied, fledgling sex and size, as well as fledging order (i.e. the order in which offspring leave the nest) have been common factors associated with divisions in care (Lessells, 
2002; Tarwater \& Brawn, 2008; Vega Rivera, Haas, Rappole, \& McShea, 2000). Until recently, brood division had only been observed during post-fledging development, but a study of the western slaty antshrike (Thamnophilus atrinucha) in Panama, found that it also occurred in $40 \%$ of nests prior to fledging (Tarwater \& Brawn, 2008). This result suggests that in different species and environments, brood division may differ in its onset and expression.

Numerous hypotheses have been proposed to explain such patterns of care and their associated function in birds. These hypotheses can be roughly classified into three groups according to the factors thought to drive brood division. The first group includes two hypotheses which predict that brood division occurs randomly without regard to fledgling sex or size however, each hypothesis foresees a different benefit from such a division. The 'parental reduction hypothesis' proposes that the primary function of brood division is to reduce the risk of total brood loss due to predation (McLaughlin \& Montgomerie, 1985; Moreno, 1984). Whereas, the 'parental efficiency hypothesis' considers brood division to be a means by which parents improve the efficiency with which they feed offspring (Anthonisen et al., 1997; Harper, 1985; Moreno, 1984; Smith, 1978).

A second group of hypotheses predicts that broods are divided on the basis of fledgling sex. The 'differential dispersal hypothesis' proposes that because male offspring tend to disperse less than daughters, male parents should preferentially care for female offspring to avoid local mate and territory competition with their sons (Clark, 1978; Gowaty \& Droge, 1991; Greenwood, 1980). Alternatively, the 'kin recognition hypothesis' proposes that parents may preferentially care for opposite-sex fledglings as such associations during early life could reinforce kin recognition and avoid future inbreeding (McLaughlin \& Montgomerie, 1985; Wheelwright \& Mauck, 1998). A third hypothesis, the 'cultural transmission hypothesis' proposes that brood division could arise if sex-specific behaviours such as song and courtship are learned from parents (Freeman-Gallant \& Rothstein, 1999; McLaughlin \& Montgomerie, 1985). Parents are predicted to care for fledglings of the same sex so that offspring may learn these behaviours.

Alternatively, a third group of hypotheses propose that fledgling size provides the basis for brood division. The 'paternity uncertainty hypothesis' predicts that females should care for the larger, most costly young, which is typically males in sexually dimorphic species (Westneat, Clark, \& Rambo, 1995; although see, Gottlander, 1987; Stamps, 1990). This is thought to be 
linked to the frequency with which extra-pair paternity occurs in birds, i.e. males may be less likely to invest in the more costly young if there is a high probability that it was sired by another male (Birkhead \& Møller, 1995). Alternatively, the 'sibling competition hypothesis' proposes that brood division might arise as a parental strategy to reduce conflict between siblings (Harper, 1985; Slagsvold, 1997). Such conflict might arise if parents differ in the amount of food they provide, resulting in conflicts between siblings over who should gain access to the "better feeder" (Slagsvold, 1997). Given its size, the larger offspring is expected to be dominant and thus, win the conflict (McRae, Weatherhead, \& Montgomerie, 1993).

The North Island robin (Petroica longipes) is a small insectivorous bird native to New Zealand forests. Like most monogamous passerines, robins exhibit biparental care during nestling development (Armstrong et al., 2000; Powlesland et al., 2000). However, different patterns of care emerge during fledgling development which are dependent on brood size. Where more than one offspring has fledged, broods are typically divided, with each parent taking responsibility for one or two fledglings. Similarly, single-fledgling broods are usually attended and fed by males only (Armstrong et al., 2000; Heather \& Robertson, 2005; Powlesland et al., 2000; Soper, 1963). As yet, brood division has not been formally documented in this species and subsequently, little is known about the timing and factors which may influence division post-fledging.

Northern and southern temperate avian species are well known to differ in several aspects of their life histories, including patterns of parental care (Russell, 2000). For instance, periods of post-fledging care are longer amongst southern passerine species compared to northern species irrespective of diet, habitat and migration pattern (Russell, Yom-Tov, \& Geffen, 2004). At present, the brood division literature is based on species breeding in northern latitudes, with the exception of a study conducted in Australia with the cooperatively breeding passerine, the white-browed scrubwren (Sericornis frontalis) (reviewed in Leedman \& Magrath, 2003). Thus, further studies of brood division in austral species are necessary to increase our knowledge of this specialised parental care strategy. Doing so may potentially offer new insights into the timing of and factors affecting the expression of brood division.

The present study is the first detailed examination of brood division in a New Zealand passerine, the North Island (NI) robin. Across two breeding seasons (2014-2015 and 20152016), feeding interactions between parents and offspring were examined during nestling and 
fledgling development. This study had two aims: firstly, to determine if there was evidence for onset of brood division at the nestling stage (i.e. preferential feeding by either parent) as this has only been documented in one species to date (slaty antshrikes; Tarwater \& Brawn 2008). Previous brood division studies have examined whether fledgling characteristics such as size or sex are correlated with the sex of their main caregiver (Tarwater \& Brawn, 2008; Vega et al., 2007; Wheelwright, Tice, \& Freeman-Gallant, 2003). Determining what factors may influence these divisions of care is an important step toward understanding what advantages such strategies confer to the parties involved. Thus, the second aim of this study was to establish whether broods were divided based on fledgling characteristics (sex or size), or divided randomly between parents.

\subsection{Methods}

\subsubsection{Study site and species}

Observations of parental feeding by NI robins were conducted at Zealandia Wildlife Sanctuary, Wellington $\left(41^{\circ} 18^{\prime} \mathrm{S}, 174^{\circ} 44^{\prime} \mathrm{E}\right)$. The sanctuary consists of 225 ha of exotic and native forest that is enclosed by a mammalian exclusion fence. In 2001 and 2002, a total of 76 NI robins were translocated from Kapiti Island (4050'S, $\left.174^{\circ} 56^{\prime} \mathrm{E}\right)$ to Zealandia and the population has since been breeding successfully (Small, 2004). In 2008, the estimated density was between 2.3 and 3.4 individuals/ha (i.e. approximately 500-765 birds) (McGavin, 2009). A subset of the robin population have been individually banded and are monitored during the breeding season as part of a long-term study on robin cognition and fitness (Shaw, Boogert, Clayton, \& Burns, 2015). Data utilised in subsequent analyses pertaining to the 2014-2015 breeding was thus, collected by RS Shaw and collaborators. All other data were collected by LL Clark.

Males and females typically form stable, monogamous pairs and produce an average of two broods per breeding season (Armstrong et al., 2000). Robins begin nesting in September, with final clutches typically laid by January (Armstrong et al., 2000). Only females build nests; the location of nests can vary between depressions in embankments, tree crowns and the forks or branches of live trees and shrubs (Armstrong et al., 2000; Powlesland et al., 2000). Clutches of one to three eggs are incubated by females for 17 to 21 days; males assist females during this period through regular provisioning (Armstrong et al., 2000; Powlesland et al., 2000). Only 
females brood young, while both parents contribute to provisioning and care of nestlings for 19 to 21 days (Armstrong et al., 2000; Powlesland et al., 2000).

Young are largely immobile upon leaving the nest; being poor fliers, fledglings tend to perch high in the canopy and are fed at these perches by parent(s) (Powlesland, 1983). Two to three weeks after fledging, young are able to fly proficiently and forage independently on the ground. However, fledglings will typically follow and beg from adult(s), with parental feeding ceasing 4.5 to 7 weeks after fledging (Armstrong et al., 2000).

Chicks were individually colour-banded approximately 10-12 days after hatching (three plastic coloured bands and one metal band, two bands per legs). Bands were supplied by the Department of Conservation's National Banding Office. While nestlings were removed from the nest for banding, three pin feathers (i.e. a developing feather) were plucked using tweezers and three measurements were recorded: weight, tarsus and wing chord length. Feathers allowed for subsequent sex determination analyses. Samples were submitted to EcoGene (Landcare Research New Zealand Limited, Auckland, http://www.ecogene.co.nz/) and gender determination was performed using the PCR technique described by Griffiths et al. (1998). The research was approved by the Victoria University of Wellington Animal Ethics Committee and conducted under permit from the Department of Conservation (Authorisation number: 38497FAU).

\subsubsection{Parental care during nestling development}

In 2015-2016, parental feeding behaviour was recorded at 17 nests. Only nests that could be safely accessed by standing at full height or by using a step ladder were observed. A camera (HDR-AS20 Action Cam, Sony, Tokyo, Japan) was placed between 0.3 to $1 \mathrm{~m}$ from the nest (depending on the availability of suitable attachment locations), 15 days after nestlings hatched (hatch date $=$ Day 1 ). Recordings began at approximately 0830 and continued for one to two consecutive hours (dependent on battery life).

Recordings were used to calculate the frequency of male and female feeding visits and the identity of nestlings receiving the feeds. The feeding parent could be identified by its unique colour-band combination; otherwise, males were distinguished from females by their darker plumage colour. Of the 17 nests filmed, three contained one nestling and 14 contained two. 
Nestling colour-bands were rarely seen due to the cup-shape of nests; thus, nestlings were named ' $\mathrm{A}$ ' or ' $\mathrm{B}$ ' based on their position in the nest at the start of the recording (left or right respectively) and their relative position was used to identify individual nestlings for the duration of the observation.

\subsubsection{Post-fledging care and brood division}

In 2014-2015 and 2015-2016, feeding interactions between parents and fledged offspring were documented. Following fledging, each offspring was typically cared for by just one of its parents. These parent-offspring pairs were identified by observing naturally occurring parental feeding behaviour and offspring begging and following behaviour toward parents. Additionally, parents typically fed their fledglings on different parts of the shared breeding territory which aided in identifying which parent cared for which offspring. Parent-offspring pairings were verified using feeding observations, both opportunistic and scheduled. Opportunistic observations, whereby the identity of and frequency of feeds between a parent and offspring were noted if birds were seen during other monitoring checks (e.g. of neighbouring territories), were the common across both seasons. Scheduled observations differed slightly between the two breeding seasons.

In 2014-2015, fledgling possession observations were conducted intermittently during the first four weeks post-fledging. During these sessions, both parents and their fledged offspring were enticed into the same area where an observer offered each parent a fixed number of mealworms (Tenebrio molitor larvae) and recorded which fledgling the parent shared the mealworms with. In 2015-2016, feeding observations were extracted from weekly sessions (up to 12 weeks after fledging) to examine the development of caching behaviour in fledglings. Both parents and their associated offspring were not always present in the same area during these observations but as before, the number of mealworms shared by each parent to particular offspring was recorded.

\subsubsection{Statistical analysis}

Analyses were conducted in $\mathrm{R}$ version 3.2.2 (The R Foundation for Statistical Computing, Vienna, Austria, http://www. r-project.org) whereas, non-parametric tests were calculated by hand (Mundry \& Fischer, 1998). Alpha is 0.05 for all tests. 


\section{Nestling stage}

Before assessing whether parents were biased in their care toward a particular nestling, it was necessary to establish whether male and female parents differed in their feeding rates during the late (day 15) nestling stage. This was achieved using a generalised linear mixed model (GLMM) with Poisson error distribution and log link function ( $\mathrm{R}$ package lme4). The number of parental feeding visits was the response variable, with the total recording length included in the model as an offset variable. The total recording length varied between nests; therefore, it's incorporation into the model as an offset variable made parental feeding visits proportional to the unit of observation. Parent sex (where $0=$ male and $1=$ female) was included as a fixed factor and parent identity nested within nest identity was included as a random effect to account for there being two feeding rates from each nest, one from each parent.

If brood division begins during the nestling period, then there should be evidence that each parent favours a particular chick across feeding bouts within an observation. For broods with two nestlings, only broods where nestlings could be reliably identified in recordings were considered for analysis thus, only 10 of the 14 broods observed were analysed. Chick A was defined as the nestling which received the greater proportion of male feeding visits, while Chick B was the nestling which received the lesser proportion of male feeding visits. To test for preferential feeding, male and female parents were compared for their relative investment in Chick A using a Wilcoxon Signed-Ranks test. Additionally, a separate Wilcoxon SignedRanks test was used to compare male and female parents for their relative investment in Chick B.

\section{Fledgling stage}

In this study, brood division was defined as the division of broods larger than one into smaller family units fed exclusively by one parent. For a brood to be classified as divided, each of the two parents had to feed at least one fledgling more frequently than the random expectation of equal numbers of feeds to each fledgling (Draganoiu, Nagle, Musseau, \& Kreutzer, 2005; Kopachena \& Falls, 1991). To determine if each parent had a preferred chick within the brood, separate chi-square tests were performed per parent per brood comparing the observed number of feeds that a parent made to each fledgling against the expected number of feeds if the parent was distributing feeding visits equally between offspring ( $n=37$ broods). An individual level approach to analysis was taken, given that the aim was to determine if each parent exhibited 
preferential care toward particular offspring post-fledging. For offspring banded post-fledging, only feeds recorded following banding were considered. Broods that met this criterion were considered divided. However, if only one parent had a preferred fledgling (and the other parent fed both fledglings equally) the brood was classified as partially divided. For broods where only one offspring fledged, a binomial two-tailed test was used to test for division in care between parents. For each fledgling, the feeding contribution (number of feeding events to fledgling) made by each parent was compared ( $n=16$ broods). The null hypothesis being that there is no difference in the contributions of male and female parents to the care of the single fledgling (biparental care).

The analysis of the factors influencing brood division (described below) only included fledglings from divided broods. In cases where one parent fed two fledglings (e.g. when brood size $=3$ ), only the fledgling that received the most feeds was included in ensuing analyses. Only broods where greater than five feeding events were observed were included in this analysis. Single fledgling broods were not included in the subsequent analysis.

Previous studies of avian brood division have found that fledgling sex and size may influence which parent is more likely to the primary caregiver for a particular fledgling (reviewed in Lessells, 2002; Slagsvold, 1997; Vega Rivera et al., 2000). To determine whether fledgling characteristics influenced the gender of caregivers at brood division, a GLMM with a binomial distribution and logit link function was used. Parent sex was used as the response variable (where $0=$ male and $1=$ female). The fixed factors included in the model were fledgling sex $(0=$ male and $1=$ female), relative size (i.e. the sibling with the larger tarsus measurement and/or weight during banding; $0=$ large and 1 = small) and their interaction. Season (20142015 and 2015-2016), caregiver identity (ID) nested within parent ID were included as random terms. Caregiver ID allowed for the consideration of particular individuals which appear in the sample more than once as a result of having sired multiple broods. Only parent-offspring pairs from divided and partially divided broods were considered in this analysis ( $n=45$ pairs from 27 broods). Fledglings from both heterogenous (male-female fledglings) and homogeneous (male-male, female-female) broods were included; the inclusion of fledglings from homogeneous broods increased the dataset for the consideration of the effect of fledgling size on caregiver sex. However, parent-offspring pairs were excluded if fledgling sex and/or size was not known. Inferences were based on the full model to reduce the rate of type-1 error and biased effect size estimates (Forstmeier \& Schielzeth, 2011). 
Finally, the relationship between offspring sex and size was examined using a GLMM with a binomial distribution and logit link function was used. Relative size (where $0=$ large, $1=$ small) was used as the dependent variable. Offspring sex $(0=$ male, $1=$ female $)$ was treated as an explanatory variable. Additionally, season (2014-2015 and 2015-2016) and fledgling identity nested within nest identity were included as random terms. Only broods with mixed offspring sex were considered $(n=23)$.

\subsection{Results}

\subsubsection{Parental feeding at nestling stage}

A combined total of over 63 hours of recordings were made at 17 nests on Day 15 posthatching. Male and female parents provisioned nestlings at similar rates; male provisioning rate was 5.625 feeding visits per hour and female provisioning rate was 4.464 (feeding rate: GLMM, parent sex effect: $z=-1.539, \mathrm{df}=1, p=0.124)$. Additionally, there was no evidence that male and female parents bias their feeds toward particular nestlings. In a comparison of relative parental investment in particular nestlings, male and female parents were comparable in the proportion of feeding visits they provided to each nestling (Wilcoxon Signed-Ranks test, Chick A: $n=10, t=12, p>0.05$; Chick B: $n=10, t=12, p>0.05$ ).

\subsubsection{Parental feeding at fledgling stage}

Broods producing a single fledgling were common within this population of NI robins $(40.3 \%$; $25 / 62$ broods). When comparing the feeding contribution made by each parent to the single fledgling, differences in parental feeding rates were observed for $75 \%$ of cases (12/16 broods; see Appendix 1). In the majority of these broods, care was primarily given by the male parent (10/12 broods, $87.5-100 \%$ of feeds to chick provided by male parent) (Appendix 1). In the remainder of broods, no difference in the feeding contribution by either parent was detected $(n$ $=4)$.

Of the remaining broods with two or more fledglings, three patterns of post-fledging care were recorded. Firstly, most broods were divided (40.5\%; 15/37); i.e. within a particular brood, each parent preferentially cared for at least one fledgling (see Appendix 2). Secondly, partial 
division occurred in $35.2 \%$ (13/37) of broods, where only one parent was found to preferentially feed at least one fledgling (Appendix 2). In these instances, female parents were just as likely as males to be the primary caregiver to the favoured nestling (Chi-squared test: $\chi^{2}$ $=0.039$, df $=1, p=0.844)$. Finally, in the remaining nine broods $(24.3 \%)$ there were insufficient feeding observations to show that either parent exhibited preferential care toward particular chicks (Appendix 2); thus, care patterns in these broods were considered unknown and excluded from subsequent analyses. No broods were considered "undivided", i.e. excluding broods with insufficient feeding observations, there were no instances where both parents exhibited no preferential feeding toward a particular fledgling.

The interaction between fledgling sex and size was found to have a significant effect on caregiver sex following brood division (GLMM: $z=2.878$, $\mathrm{df}=1, p=0.004, n=45$ parentoffspring pairs; Table 1). Offspring were often cared for by parents of the same sex as themselves. Thus, male offspring (typically larger than female siblings) were usually associated with their male parent and female offspring (typically smaller than male siblings) were usually associated their female parent (Figure 1).

Table 1. Model generated from GLMM (binomial distribution with a logit link function) which examines the effect of offspring sex and size on caregiver sex following brood division. Male parent was the reference value. Parent ID nested within Nest ID and Season (2014-15, 2015-16) were included as random factors. Asterisks $\left(^{*}\right)$ denote interactions between variables.

\begin{tabular}{lcccc}
\hline & Estimate & $\mathrm{SE}$ & $z$ & $p$ \\
\hline Intercept & -10.674 & 3.036 & -3.515 & $<0.001$ \\
Fledgling sex $^{*}$ size & 20.854 & 7.246 & 2.878 & 0.004 \\
Fledgling size $^{\mathrm{a}}$ & 0.363 & 3.972 & 0.091 & 0.927 \\
Fledgling sex $^{\mathrm{b}}$ & 0.095 & 4.783 & 0.020 & 0.984 \\
\hline
\end{tabular}

${ }^{a}$ Size was a categorical variable (large or small) with large as the reference value.

${ }^{\mathrm{b}}$ Sex was a categorical variable (male or female) with male as the reference value.

In the analysis of the relationship between offspring sex and size, offspring sex was a significant influence on the classification of nestling size (large vs. small: GLMM, offspringsex effect: $z=2.082$, df $=1, p=0.037$ ). Therefore, in broods containing both sexes, male offspring had a higher probability of being the largest nestling compared to female offspring. 


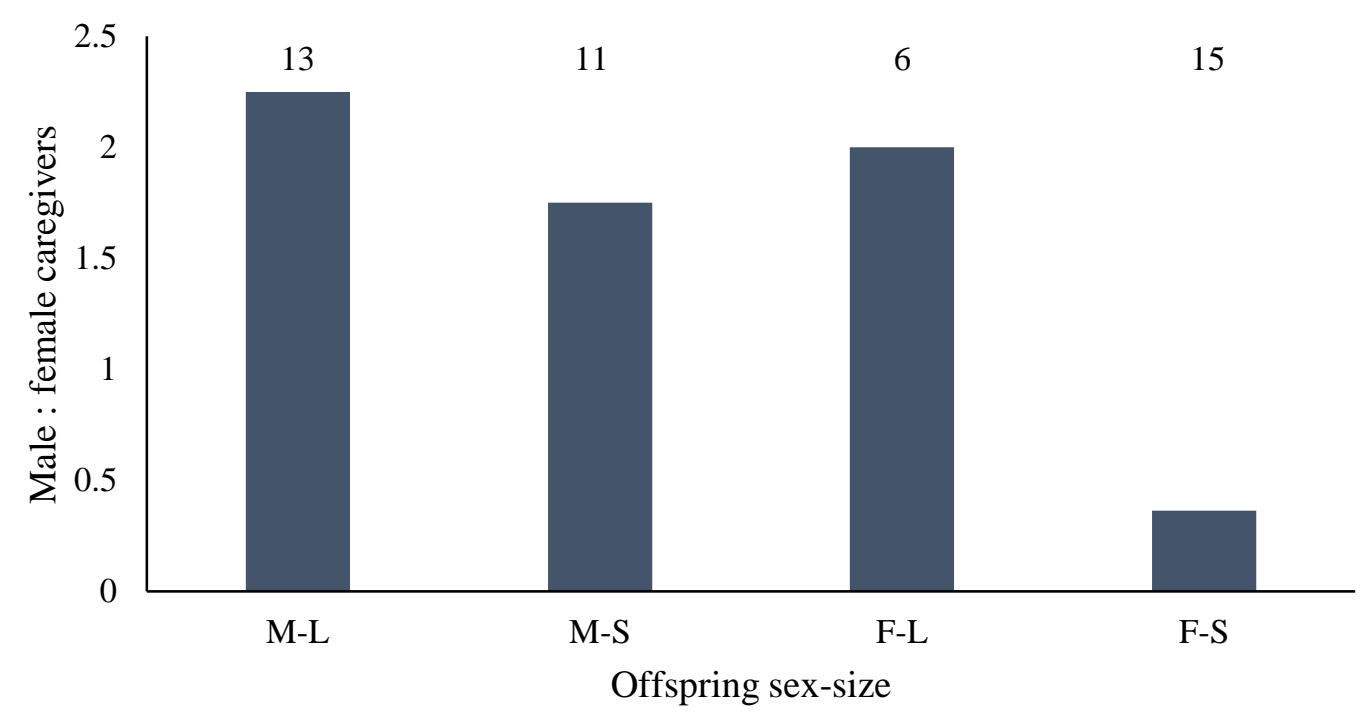

Figure 1. Ratio of male to female caregivers at brood division for four offspring types: male-large (M-L), male-small (M-S), female-large (F-L) and female-small $(\mathrm{F}-\mathrm{S})$. Ratio $=1$ : no caregiver bias; ratio $>1$ : male caregiver bias; ratio $<1$ : female caregiver bias. Numbers above bars denote sample size, i.e. number of fledglings.

\subsection{Discussion}

This study is the first quantitative evidence for brood division in a New Zealand passerine, the North Island robin. Brood division does not occur until after young have left nest. During the later stages of nestling development, parents cooperatively care for offspring and similar parental feeding investment is observed for both male and female parents, i.e. parents distribute their provisioning effort evenly among offspring. Post fledging, most offspring received the majority of care from only one of their parents (hereafter the 'primary caregiver'). In singlefledging broods, primary caregivers to offspring were primarily male parents. In broods with two to three fledglings, primary caregivers to offspring were usually of the same sex as the fledgling.

While joint parental care during nestling development does not necessitate equal contributions by parents, the majority of studies report that this is typically the case (see Woodard \& Murphy, 1999). In a comparison of songbirds, Woodard \& Murphy (1999) found that for most monogamous species, males and females had similar feeding contributions to offspring. Likewise in this study, male and female robins did not differ in their relative feeding investment of nestlings. Even for single-chick broods, parents appeared to share feeding responsibilities equally between them at day 15 of development. These results would suggest that, preferential 
feeding and brood division do not occur until after young leave the nest. However, nestling observations were conducted approximately five days prior to fledgling; therefore, it is possible that care biases seen post-fledging may arise immediately prior to fledging, as has been reported by Smith (1978) for song sparrows (Melospiza melodia). Future studies might consider examining parental feeding patterns in robins closer to the time of fledgling to test this possibility.

The 'parental reduction hypothesis' predicts that brood division occurs randomly with regard to fledgling characteristics. This random distribution of offspring is thought to reduce the risk of total brood loss due to predation (McLaughlin \& Montgomerie, 1985; Moreno, 1984). Male and female parents typically feed their designated young on different parts of the shared breeding territory thus, a predator tracking one parent will potentially only be a risk to half the family (McLaughlin \& Montgomerie, 1985; Moreno, 1984). Results of this study provide some support for this hypothesis. Although fledglings were not randomly distributed among parents, there was clear spatial segregation between matriarchal and patriarchal family sub-units. Male and female parents tended to occupy and feed their young in different areas of the shared territory, typically the areas that they occupied outside of the breeding season. Predation risk was very real as moreporks (Ninox novaeseelandiae), predatory owls which roost in the understory by day, were often seen in throughout the study area. Brood division may therefore assist robin parents in minimising the risk of predation.

The sibling rivalry hypothesis postulates that brood division may occur, if as the result of sibling competition, the largest offspring monopolizes access to the best feeder (Slagsvold, 1997). Each parent is equally related to all its young thus, to maximise reproductive success it is in a parent's best interest to equally share resources amongst all progeny (Trivers, 1974). However, offspring are more related to themselves than to their siblings and are thus, inherently selfish and will seek to acquire more than its fair share of parental resources (Trivers, 1974). Although large offspring were often cared for by male parents post-fledging, male and female parents provisioned nestlings at similar rates on Day 15 post-hatch. As such, males would not be considered the "best feeder"; however, male provisioning rates could have been greater than females in the remainder of the nestling period so caution must be used in considering this result. An additional consideration is the timing of brood division. In this study, brood division seemed to occur around the time that young left the nest and this finding is supported by previous observational work of New Zealand robins (Armstrong et al., 2000; Higgins \& Peter, 
2002; Soper, 1963). For up to two weeks following nest departure, offspring remain largely stationary in the forest canopy receiving regular feeding visits from parent(s) (pers. obs). As such, it is unlikely that a fledgling could easily monopolise access to a particular parent if it is a weak flyer and unable follow adults. The results of this study therefore, provide limited evidence in support of the sibling rivalry hypothesis.

Another common hypothesis, the 'cultural transmission' hypothesis, proposes that broods are divided on the basis of fledgling sex. Parents are predicted to care for fledglings of the same sex if sex-specific behaviours such as foraging and song are learned from parents (FreemanGallant \& Rothstein, 1999; McLaughlin \& Montgomerie, 1985). New Zealand robins are one of a very small number of species in the southern hemisphere which cache or hoard food (Vander Wall, 1990). Both sexes cache food however, outside of the breeding season males are competitively dominant to females and they will displace females from food sources (Alexander et al., 2005; Burns \& Steer, 2006). To ensure their share of limited resources, females may employ different foraging strategies, such as moving out of sight before caching, to reduce the risk of cache-pilfering by males (Higgins \& Peter, 2002). Juvenile female robins who witness such strategies in their female parents, may be better able to provision for themselves once independent. Additionally, male robins are notable songsters who can be heard singing in their territories year-round but particularly during the breeding season (Higgins \& Peter, 2002). Singing indicates territorial occupancy and is used to attract a mate (Heather \& Robertson, 2005); therefore, the post-fledging care period may be crucial for song learning in juvenile males prior to their dispersal from the natal territory.

Male-only care in single fledglings broods may enable females to initiate a subsequent clutch (Verhulst \& Hut, 1996; Weatherhead \& McRae, 1990). Removal experiments with male eastern bluebirds (Sialia sialis) suggest that offspring can be successfully cared for by just one of their parents (Gowaty, 1983). Additionally, in studies where males have exclusively cared for fledglings from early broods, subsequent nesting attempts ensued (Edwards, 1985). However, this hypothesis finds little support in this study as subsequent nesting attempts were seldom observed, i.e. females re-nested in only 3 out of 10 cases where males provided the majority of care in single-offspring broods. In NI robins, time in season may have a greater influence on subsequent breeding attempts. Breeding in New Zealand robins is restricted to just a few months of the year (Sept-Feb, Higgins \& Peter, 2002). Thus, given the extended periods with which care is provided during incubation (17-21 days), nesting (17-21 days) and 
post-fledging (up to 7 weeks) (Armstrong et al., 2000), there may not be sufficient time for females to re-nest even if they are released from caring for current progeny. Therefore, maleonly care in single-offspring broods may have other benefits and functions; for instance, it may allow male robins to offset the high investment shown by females in the initial stages of the brood where she was solely responsible for nest building and incubation (Armstrong et al., 2000).

The majority of studies have focused on explaining the incidence and function of brood division with regard to biological factors such as offspring characteristics (Anthonisen et al., 1997; Vega et al., 2007; Wheelwright et al., 2003). However, environmental factors such as food availability may be influential in shaping these parental care strategies (Price \& Gibbs, 1987). For instance, the breeding biology of two species of Darwin's finches (Geospiza fortis and G. scandens) was studied on the island of Isla Daphne Major (Galapagos, Ecuador) between 1979 and 1983 (Price \& Gibbs, 1987). Authors found inter-annual variation in the extent of brood division with regards to food availability. In years where heavy rainfall resulted in an abundance of caterpillars, the main component of juvenile diets, brood division rarely occurred (Price \& Gibbs, 1987). Additionally, Slagsvold (1997) found that in studying parental feeding patterns in two populations of the American robin (Turdus migratorius), parental strategies were highly responsive to food availability. These studies highlight the flexibility in which these care strategies can be employed with regard to changes in resources. Future studies of brood division in NI robins should therefore aim to study post-fledging care in populations across a range of environmental and biological conditions to determine the flexibility with which these care strategies exist within the species. This may be achieved by comparisons of different North Island robin populations or between North Island and South Island robins (Petroica australis), which are biologically very similar (Higgins \& Peter, 2002).

Brood division has rarely been documented amongst species in the southern hemisphere (Lessells, 2002). However, the results of this study suggest that brood division in NI robins follows a similar pattern to northern hemisphere species. Broods of NI robins were divided shortly after fledging and on the basis of offspring characteristics. Likewise, birds in northern temperate regions have also shown these patterns (Draganoiu et al., 2005; Wheelwright et al., 2003). The similarities with which brood division appears to be expressed suggests that brood division confers the same adaptive advantages for robins as has been claimed for northern hemisphere species, e.g. reduction predation risk, the transmission of sex-specific behaviours 
from adults to young, etc. (McLaughlin \& Montgomerie, 1985; Moreno, 1984; Wheelwright et al., 2003).

In contrast to the period of nestling development, much less is known about parental care of avian young from fledging to independence (Smith, 1978; Weatherhead \& McRae, 1990). This is largely a result of the increasing difficult with which one can follow and observe interactions between parent and offspring during this period. Thus, this study makes a valuable contribution to furthering our understanding of the behaviour of parents tending to young following their departure from the nest. Additionally, it provides the first quantitative evidence for the occurrence of brood division in a New Zealand passerine, the North Island robin. The patterns that were found offer support to the 'cultural transmission hypothesis', which suggest that fledgling sex and size are influential factors in the division of robin broods post-fledging. Regardless of the mechanism with which broods are divided, there are obvious benefits to robins dividing post-fledging parental care, such as the reduction of predation risk and the opportunity for young to learn sex-specific behaviours prior to leaving the natal territory. As this is only the second brood division study to be conducted in the southern hemisphere, there remains numerous research opportunities to understand how social and environmental factors mould this parental care strategy among birds. 


\title{
Chapter 3: The Ontogeny of Food-Caching Behaviour in North Island robins (Petroica longipes)
}

\begin{abstract}
3.1 Abstract
Hoarding or caching behaviour is a widely-used paradigm for examining a range of cognitive processes in birds, such as social cognition and spatial memory. However, much is still unknown about how caching develops in young birds, especially in the wild. Studying the ontogeny of caching in the wild will allow researchers to examine how this behaviour develops without the constraints of laboratory conditions and in ecologically relevant conditions. This study examines the ontogeny of food caching behaviour in wild North Island robins (Petroica longipes). Thirty-four juveniles were observed for 12-weeks following fledging and the development of caching and cache retrieval was documented. Mixed models were used to explore the effect of juvenile age, sex and parental care environment on the onset and development of caching, cache retrieval, number of cache sites used and the time spent handling mealworms prior to caching. Juveniles began caching mealworms shortly after achieving foraging independency. Caching rate increased and handling time decreased with age. Juveniles spontaneously began retrieving caches as soon as they had begun to cache and their retrieval rates remained constant throughout development. Likewise, the number of sites used by juveniles did not change with age. Juvenile sex and parental care environmental did not influence the development of any of the caching behaviours. Results suggest that many aspects of caching in North Island robins are likely to be innate, but that age and experience have an important role in the development of adult caching behaviours.
\end{abstract}

\subsection{Introduction}

As with many natural resources, food availability can vary on a daily, seasonal or random basis. When food becomes temporarily abundant, many animals will respond by hoarding or caching food in their environment, thereby preserving the resource for future consumption (Vander Wall, 1990). As such, species that hoard food possess a complex suite of physical skills for creating caches (e.g. preparation, transportation, etc. of food; Bossema, 1979; Kallander, 2007; Vander Wall \& Balda, 1981), and cognitive skills for remembering the location of caches for subsequent retrieval (e.g. spatial memory; Balda \& Kamil, 1992; Jacobs \& Liman, 1991). In addition to the ease with which caching can be induced in laboratory environments, this 
complexity has made caching a popular model for studies of avian cognition and foraging (Clayton, Dally, \& Emery, 2007; Gerber, Reichman, \& Roughgarden, 2004; Korpimaki, 1987).

However, despite the prevalence with which caching is used as an experimental paradigm by comparative cognition researchers, only a few detailed ontogenetic studies of caching behaviour have been made (Vander Wall, 1990). The earliest study was conducted in southern Norway, with wild crested tits (Lophophanes cristatus) and willow tits (Poecile montanus) (Haftorn 1992). Field observations in 1950 and 1987-90, reported that the food caching behaviour in these species arose approximately two weeks after young left the nest (Haftorn, 1992). At its onset, food storing acts were "incomplete", i.e. juveniles pretended to deposit items at sites and/or immediately retrieved and consumed caches. However, within a week juveniles were observed completing food storing acts by leaving food at cache sites following placement (Haftorn 1992). Haftorn (1992) concluded that caching was largely innate within tits and that experience, rather than observational learning, was key to the development of this behaviour.

Similar results were also reported for wild pinyon jays (Gymnorhinus cyanocephalus) in Arizona, USA (Stotz \& Balda, 1995). Object caching (i.e. caching of inedible items such as rotten pinyon pine seeds and pine bark) was first observed in juveniles at 3 weeks post-fledging and was prevalent until 12 weeks post-fledging, when it was replaced by food caching. The onset of food caching behaviour coincided with the development of foraging skills as adults were rarely observed feeding young past 16 weeks post-fledging (Stotz \& Balda, 1995). Stotz \& Balda (1995) concluded that the observed shifts from caching objects to food suggested that experience, i.e. learning to distinguish between edible and inedible items, was influential in the acquisition of caching behaviour in pinyon jays.

The study of crested and willow tits (Haftorn, 1992) and pinyon jays (Stotz \& Balda, 1995) are the only examples where the emergence of caching behaviour has been documented in the wild. All subsequent research has shifted toward laboratory-based research tracking the development cognitive traits related to caching. For instance, ontogenetic studies of caching with magpies (Pica pica) and ravens (Corvus corax) in laboratories have focused on linking the development of skills for storing food with the acquisition of object permanence, i.e. the capacity to understand that an object can still exist while temporarily out of view (Bugnyar et al., 2007; Piaget, 1937; Pollok, Prior, \& Güntürkün, 2000). Such studies have been invaluable to 
improving our knowledge of avian cognitive abilities, but the ontogeny of caching behaviour itself still remains poorly documented. Additionally, previous ontogenetic studies of caching behaviour have been restricted to just a few groups of birds (e.g. Paridae and Corvidae spp.) and carried out in laboratory environments (Bugnyar et al., 2007; Clayton, 1992, 1994; Pollok, Prior, \& Güntürkün, 2000; Salwiczek et al., 2009). Thus, there are significant gaps in our understanding of how other avian families develop and utilise this complex behaviour, as well as how this behaviour emerges in natural settings.

New Zealand robins (Petroica spp.) are one of a few species in the southern hemisphere that are known to cache food (Vander Wall, 1990). Like many birds endemic to isolated islands, these small insectivorous passerines lack pronounced anti-predator behaviours and will fearlessly approach humans (sensu Carlquist, 1970; Maloney \& McLean, 1995). Thus, both species (North Island robin, Petroica longipes; South Island robin, P. australis) are easily observed performing behaviours that are often difficult to study in other wild passerines, i.e. mating, incubation and caching (Boulton, Richard, \& Armstrong, 2010; Burns, 2009; Powlesland et al., 2000). Adult caching behaviour has been well studied in this species but as yet there have been no studies of the development of caching in young robins (Alexander et al., 2005; Burns, 2009; Burns \& Steer, 2006; Burns \& Van Horik, 2007; Van Horik \& Burns, 2007).

The North Island (NI) robin offers a valuable opportunity to examine the development of caching in a wild passerine species that does not belong to the typically studied Corvidae and Paridae families. Therefore, the aim of this study was to examine the development of food caching in wild North Island robins. During the 2015-2016 breeding season, weekly feeding sessions were performed with 34 fledglings to observe and describe foraging and caching behaviours. A mixed model approach was used to examine the effect of fledgling age, sex and parental care environment on juvenile caching ability and three related behavioural elements: cache retrieval, site use and time spent handling items prior to caching. Previous ontogenetic studies in other species have reported a significant effect of age on caching ability therefore, age was predicted to have a significant influence on all four caching-related behaviours in robins (Bugnyar et al., 2007; Clayton, 1992; Haftorn, 1992). Fledgling sex and parental care environment were included in analyses on the basis that robins exhibit marked sexual differences in caching behaviour and provide a prolonged post-fledging care period (4.5 to 7 weeks) (Alexander et al., 2005; Armstrong et al., 2000; Van Horik \& Burns, 2007). 


\subsection{Methods}

\subsubsection{Study site and species}

Field observations were conducted with juvenile NI robins at Zealandia Wildlife Sanctuary, Wellington $\left(41^{\circ} 18^{\prime} \mathrm{S}, 174^{\circ} 44^{\prime} \mathrm{E}\right)$. The sanctuary consists of 225 ha of regenerating native forest within which introduced mammals have been removed and are prevented from returning by a specially built mammalian exclusion fence. The robin population at Zealandia was established via translocations in 2001 and 2002 from nearby Kapiti Island (4050'S, 174 56'E). The species has since been breeding successfully, with an estimated density in 2008 between 2.3 and 3.4 individuals/ha (i.e. approximately 500-765 birds) (McGavin, 2009; Small, 2004). A subset of the robin population have been individually banded and are monitored during the breeding season as part of a long-term study on robin cognition and fitness (Shaw et al., 2015).

NI robins begin nesting in September, with final clutches typically laid by January. Following nest departure at 17-21 days old, young remain in natal territories and are cared for by parents for 4.5 to 7 weeks (Armstrong et al., 2000). Young are largely immobile upon leaving the nest; being poor fliers, fledglings tend to remain perched high in the canopy and are fed at these perches by parent(s) (Powlesland, 1983). By two to three weeks post-fledging, young are able to fly proficiently and forage independently on the ground. Juveniles in this study system were identified by a unique combination of colour-bands attached 10-12 days after hatching or shortly after fledging. Additionally, three pin feathers were removed at banding and submitted to EcoGene (Landcare Research New Zealand Limited, Auckland, http://www.ecogene.co.nz/) to conduct sex determination analyses using PCR techniques described by Griffiths et al. (1998).

The diet of NI robins includes some of the world's largest terrestrial invertebrates such as giant earthworms (Lumbricidae) and flightless grasshoppers called weta (Orthoptera: Anostostomatidae). These prey are typically too large to consume whole or in one sitting; therefore, large prey are typically dismembered and pieces not immediately consumed are cached in branch-trunk axils, cavities in branches, broken tree trunks or tree fern crown (Alexander et al., 2005; Powlesland, 1980). 


\subsubsection{Field methods}

Field observations were undertaken during the austral summer of 2015-2016 to study fledgling caching development under natural conditions. Thirty-four fledglings from 23 broods were monitored on a weekly basis over a 12-week period, commencing at fledging. Parental care is typically divided between parents following nest departure, thus individual fledglings are often exclusively cared for by just one of their parents during this period (see previous chapter, Section 2.4.1). All subjects during these observations could be individually identified by coloured leg-bands.

Observations consisted of two consecutive 20 minute periods and where possible, sessions were filmed using an iPad Air 2 (Apple Inc.). During the first period, fledglings were offered up to 10 mealworms (Tenebrio molitor larvae). Fledglings less than three weeks post-fledging had limited mobility and were unfamiliar with mealworms therefore, mealworms were offered to their caregivers, which fed the items to young. Mealworms were offered in succession with a minimum interval of one minute between each presentation. The subsequent fate of each mealworm was recorded under three categories; consumed mealworms were those eaten immediately, cached mealworms were those transported to nearby tree branches or other suitable cache sites and unknown mealworms were those that were dropped and lost by subjects, or where the outcome of the mealworm was not known due to the subject moving out of sight. Additionally, the number of cache sites used and the time spent handling mealworms prior to depositing at a cache site was noted.

During the second 20 min period of an observation, no mealworms were offered to the subject. Instead, the frequency and timings of specific behaviours displayed by parents and offspring were described and documented (see Appendix 3 for details). As the primary aim of this study was to examine the development of caching behaviour, the "Food-directed behaviours" listed in Appendix 3 were the focus of subsequent analyses.

The research was approved by the Victoria University of Wellington Animal Ethics Committee and conducted under permit from the Department of Conservation (Authorisation number: 38497-FAU). 


\subsubsection{Statistical analysis}

Analyses were conducted using R version 3.2.2 using the package lme4 (The R Foundation for Statistical Computing, Vienna, Austria, http://www. r-project.org). Alpha was 0.05 for all tests.

\subsubsection{Caching}

A generalised linear mixed model (GLMM) with a binomial distribution and logit link function was used to examine the effect of fledgling characteristics and parental care type on fledgling caching. The response variable was the proportion of mealworms cached out of the total (up to 10 mealworms) offered to fledglings in a given observation session. Explanatory variables included fledgling age (a continuous variable from 1 to 12 weeks), fledgling sex (male and female), their interaction, caregiver sex (male and female) and post-fledging care duration (hereafter DOC; defined as the total number of days between the first observation of parental feeding and the last observation). Fledgling ID nested within Nest ID was included as a random factor in this GLMM and in all multivariate analyses (GLMM and LMM) described below to control for the repeated measures design (i.e. there are repeated measurements of caching effort, cache retrieval, etc. for each subject).

\subsubsection{Cache retrieval}

A GLMM with binomial distribution and logit link function was used to investigate the effect of fledgling age, sex and caregiver sex on cache retrieval rates. The response variable was the proportion of cached mealworms retrieved by the subject in remainder of the session, i.e. the 20-30 minutes after mealworms had been given to the subjects and cached. As retrieving can only occur if a bird has cached, only fledglings which had been observed caching during an observation session were included in the analysis. This reduced the sample size and as such, DOC and interactions between explanatory variables were not included in the model. Caregiver sex, rather than the period of post-fledging parental feeding (DOC), was believed to be more biologically relevant to the examination of juvenile retrieval rates as sexual differences in cache retrieval have been documented for adult robins (Van Horik \& Burns, 2007) and it was thought that this could influence juvenile cache retrieval. 


\subsubsection{Site variability}

Site variability was defined as the total number of cache sites created by a subject in a given observation session. A GLMM with Poisson distribution and log link function was used to investigate the effect of fledgling age, sex and DOC on the number of cache sites created. Only sessions where fledglings cached more than one item were considered in this analysis, as only one cache site can be created with one mealworm. The number of mealworms cached and the distribution of these items (scattered or clumped) will likely to influence the number of sites a subject will use. Therefore, to control for the effect of caching intensity on cache site number, total number of mealworms cached for each session was included as a random factor. As the above criteria limited the sample size available for the analysis, caregiver sex and interactions between the explanatory variables were not included in the model. The parental care environment was instead represented by DOC to test whether the duration of time spent closely interacting with a caregiver was more likely to affect juvenile decisions regarding cache site usage. For example, caregivers may be more likely to pilfer juvenile caches with increasing opportunities to observe juveniles caching (i.e. longer post-fledging care duration). In other species, an increased risk of pilfering is often associated with the scattering of caches (Clarkson, Eden, Sutherland, \& Houston, 1986; Male \& Smulders, 2007, 2008).

\subsubsection{Handling time}

Handling time was defined as the time in seconds spent handling mealworms prior to caching. A linear mixed model (LMM) was used to compare the mean handling time (log transformed) for 23 fledglings. As with the cache model (Section 3.3.3.1), fledgling age, fledgling sex, caregiver sex and duration of care were included as explanatory variables. Interactions between explanatory variables were not included in the model due to the low sample size.

\subsubsection{Comparing juvenile and adult caching behaviour}

To investigate whether fledglings had developed adult-like caching behaviour by the end of the 12-week observation period, the caching behaviour of adult robins was observed and compared to the juveniles' caching behaviour. Mann-Whitney U tests were used to compare the oldest juveniles (12-weeks post-fledging) to adults in terms of their caching effort, retrieval rates, cache site variability (number of sites used/number of caches made) and pre-caching 
handling time. Each of these non-parametric tests were calculated by hand, due to the small sample sizes (Mundry \& Fischer, 1998).

Observations of adult caching behaviour were collected from 35 individuals ( 20 males, 15 females) during the period of May to August, 2016. This period covers the majority of the nonbreeding season when robins are reported to cache more food (Steer \& Burns, 2008). Protocol for observations followed that described for juveniles in Section 3.3.2 however, the maximum number of mealworms offered was nine compared to the ten for juveniles.

\subsection{Results}

Juveniles cached $14.199 \pm 0.012 \%$ (mean \pm SE) of the mealworms that were offered during feeding sessions, while the remaining mealworms were predominantly consumed $(0.038 \pm$ $0.006 \%$ mealworms were lost or had unknown outcomes). Mealworms were always cached intact and no effort was made to conceal caches once the item was deposited at a cache site (i.e. by covering with foliage etc.).

Most caches sites were above the ground in branch-trunk axils, cavities in branches, broken tree trunks or tree fern crowns (Figure 2). However, on a few occasions fledglings cached mealworms on the ground, i.e. prey was purposely placed on a bare patch of soil or on a branch on the ground. These incidences were isolated to just four juveniles from three different broods over a two-week period in late February to early March. The juveniles ranged in age from 3-9 weeks at the time of observations. Cache sites used by adults were similar to those described above for juveniles however, no adults were observed caching on the ground. 


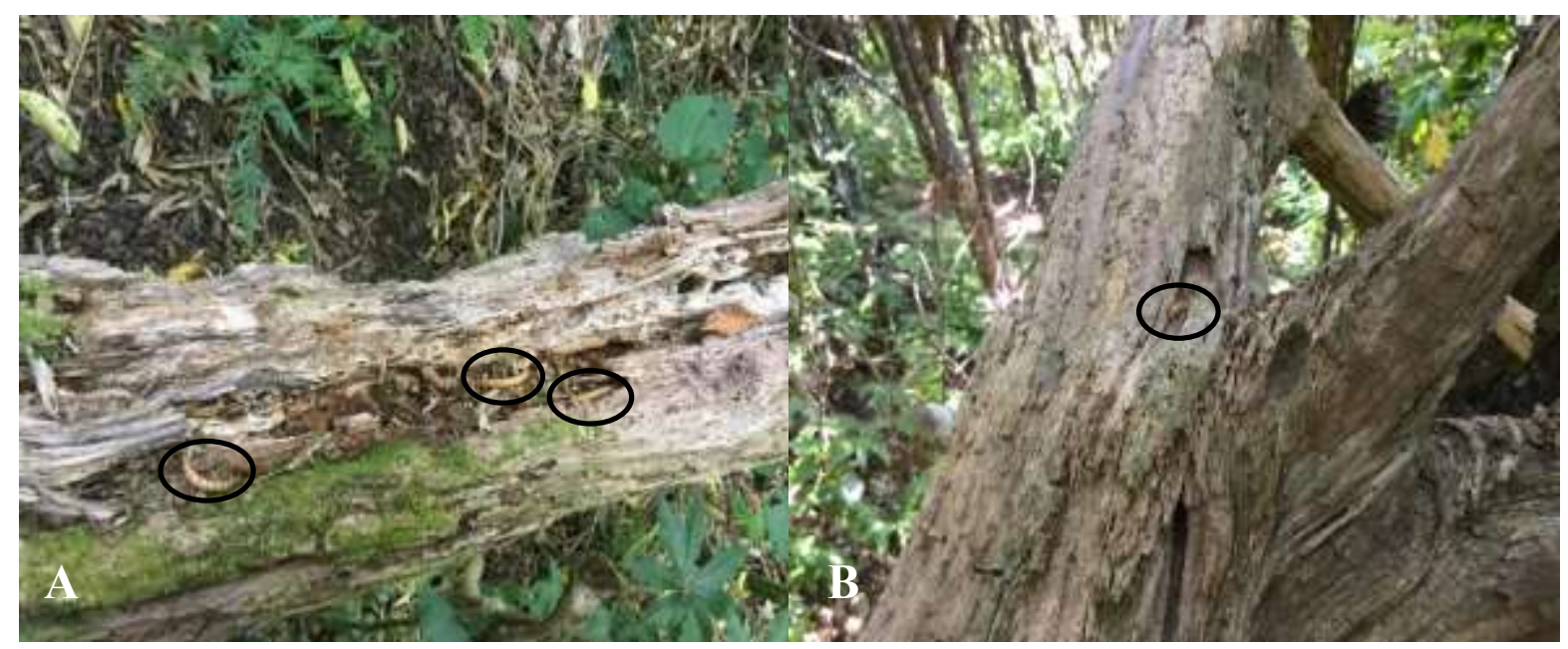

Figure 2. Examples of sites used by juvenile robins to cache mealworms: (A) a depression in a decaying tree branch and (B) a brank-trunk axil. Black circles indicate mealworms cached at these sites.

\subsubsection{Caching}

The proportion of mealworms cached out of the total number offered increased as juveniles aged (Fledgling age: $z=7.471, p<0.05$; see Appendix 4). Caching was not observed during the first four weeks of fledgling development, except for one individual (male, fledged late in the season) who cached one mealworm in both Week 3 and 4. Otherwise, fledglings typically began caching in Week 5 and by Week 10, they were caching at a rate similar to that of adults (Figure $3 A$ ). Regardless of age, caching effort did not differ between male and female fledglings (Fledgling age*sex: $z=-0.878, p=0.380$; Appendix 4). Additionally, care environment (i.e. the sex of the caregiver or the duration of post-fledging feeds, DOC) did not affect a fledglings' caching effort (Caregiver: $z=1.481, p=0.139$; DOC: $z=-0.638, p=0.523$; Appendix 4). At 12-weeks post-fledging the juvenile caching effort did not differ from the adults' caching effort (proportion of items cached: median $_{\text {fledglings }}=0.268$, range $=0.121$ $0.375)$, median $_{\text {adults }}=0.286$, range $=0.143-0.429 ;$ Mann-Whitney $U=282.5, \mathrm{n}_{\text {fledglings }}=20$, $\left.\mathrm{n}_{\text {adults }}=35, z=1.172, p>0.05\right)$. 

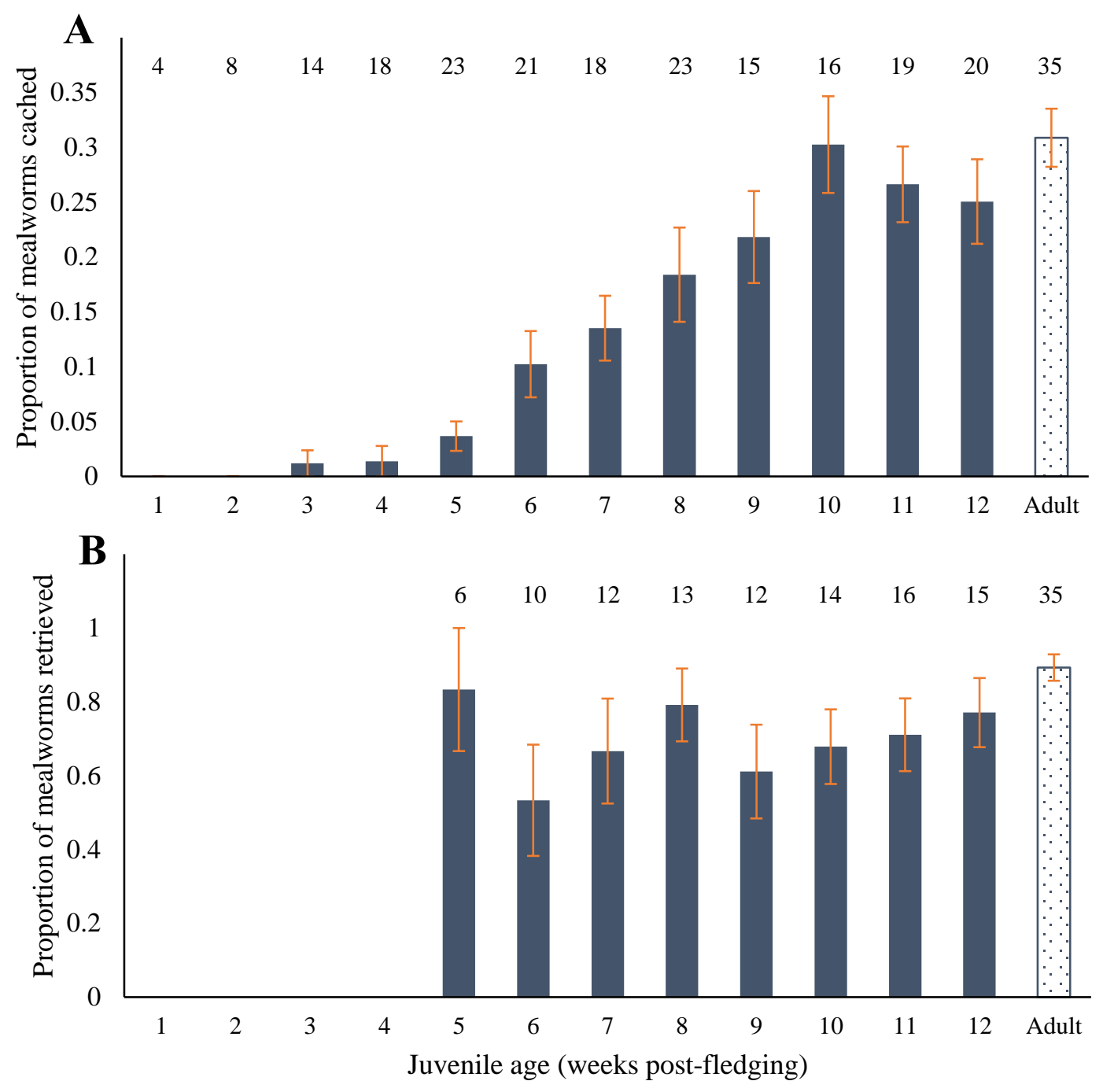

Figure 3. Mean proportion of mealworms cached (A) and retrieved (B) as a function of juvenile age (weeks since fledging). With the exception of one individual, caching began at 5 weeks post-fledging at which time cache retrieval also commenced. In both (A) and (B), adult caching and retrieval effort have been included for comparison (patterned bar). In (B), only juveniles 5 weeks or older were considered in analyses as only two instances of caching were observed in Weeks 3 and 4 (same individual, cached items were not retrieved). Numbers above bars indicate sample size, i.e. number of fledglings/adults. Error bars represent standard error.

\subsubsection{Cache retrieval}

Fledgling age and caregiver sex did not affect a juvenile's ability to retrieve a cache (Fledgling age: $z=0.719, p=0.472$; Caregiver: $z=-0.774, p=0.439$; see Appendix 5). Likewise, retrieval success was similar between male and female fledglings (Fledgling sex: $z=0.847, p=0.397$ ). Retrieval was observed as soon as the majority of birds began caching in Week 5 post-fledging 
and showed no clear pattern of change across the following weeks (Figure $3 B$ ). At 12 weeks, juvenile retrieval success was comparable to that of adults (proportion of caches retrieved: $\operatorname{median}_{\text {fledglings }}=1$, range $=0.75-1$, median $_{\text {adults }}=0.893$, range $=1-1 ; \mathrm{U}=244.5, \mathrm{n}_{\text {fledglings }}=15$, $\left.\mathrm{n}_{\text {adults }}=35, z=0.370, p>0.05\right)$.

\subsubsection{Site variability}

Site variability was the total number of cache sites created by a subject during an observation session; only instances where subjects cached more than once were assessed. Site variability was similar amongst fledglings, regardless of their age or sex (Fledgling age: $z=0.620, p=$ 0.535; sex: $z=-0.362, p=0.717$; see Appendix 6; Figure 4). Likewise, duration of postfledging care did not influence the number of sites used by fledglings $(z=0.872 ; p=0.383$; Appendix 6). At their oldest (i.e. 12 weeks post-fledging), juveniles did not differ from adults in the number of different cache sites used relative to the number of mealworms cached (median and range: fledglings $=0.667,0.5-1$, adults $=1,0.667-1$; Mann-Whitney $U=118.5$, $\left.\mathrm{n}_{\text {fledglings }}=14, \mathrm{n}_{\text {adults }}=24, z=1.483, p>0.05\right)$.

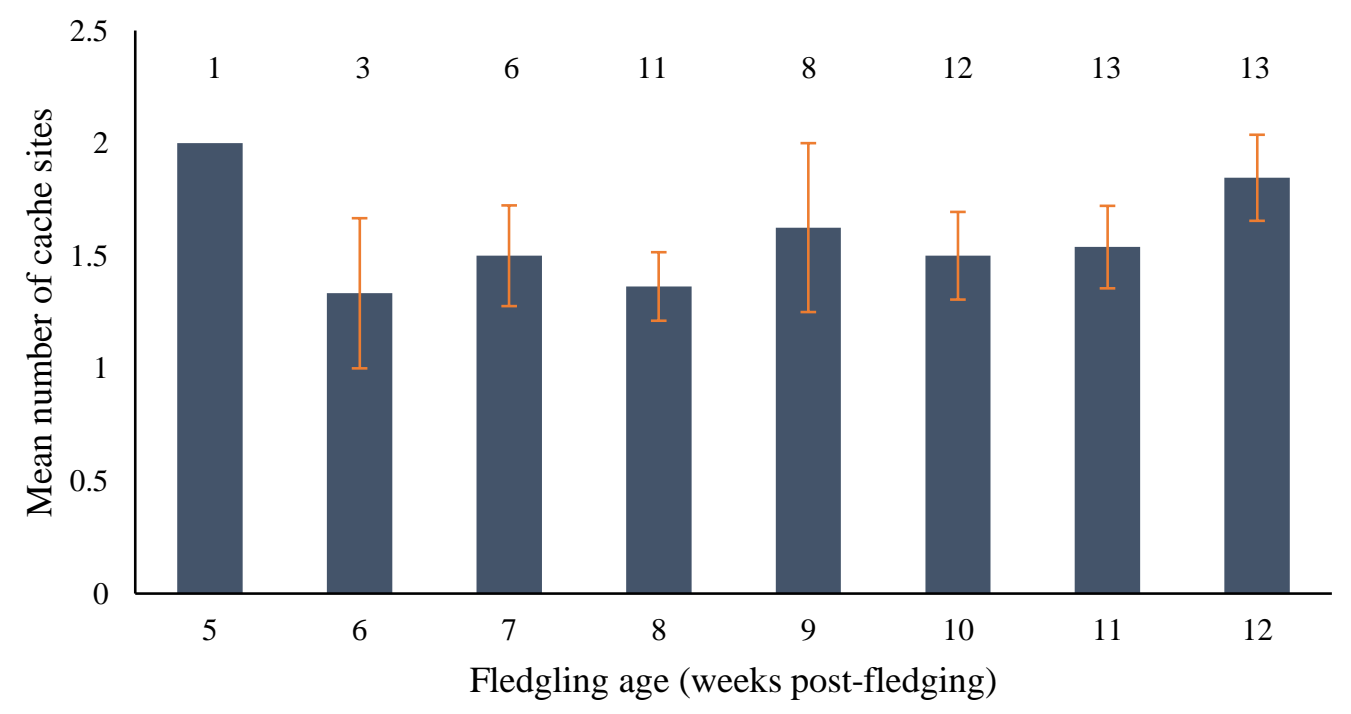

Figure 4. Mean site variability (the number of cache sites used) as a function of fledgling age (mean $\pm \mathrm{SE}$ ). Only instances where fledglings cached more than one mealworm were included. Numbers at the above bars indicate sample size, i.e. number of fledglings. Error bars represent standard error. Mean and standard error could not be calculated for 5-week data as sample size $=1$. 


\subsubsection{Handling time}

Handling time, the time in seconds between the taking of a mealworm and its placement at a cache site, decreased as fledglings aged $(t=-5.000, p<0.05$; see Appendix 7). A significant decrease was observed at 7 weeks but thereafter, handling time remained consistent (Figure 5). Fledglings with male caregivers tended to have longer handling times however, this effect was not significant $(t=2.030, p=0.052$; Appendix 7). Duration of care and fledgling sex did not influence the length of time spent handling items (DOC: $t=1.776, p=0.087$; Fledgling sex: $\mathrm{t}$ $=-0.543, \mathrm{p}=0.590$; Appendix 7). Despite handling time decreasing with age, juveniles at 12weeks post-fledging still had a median handling time that was longer than that of the adults $($ median and range: fledglings $=30.3 \mathrm{~s}, 26.0-42.0 \mathrm{~s}$, adults $=24.0 \mathrm{~s}, 19.7-29.0 \mathrm{~s}$, MannWhitney $\left.\mathrm{U}=173, \mathrm{n}_{\mathrm{fledglings}}=16, \mathrm{n}_{\text {adults }}=35, \mathrm{z}=-2.162, \mathrm{p}<0.05\right)$.

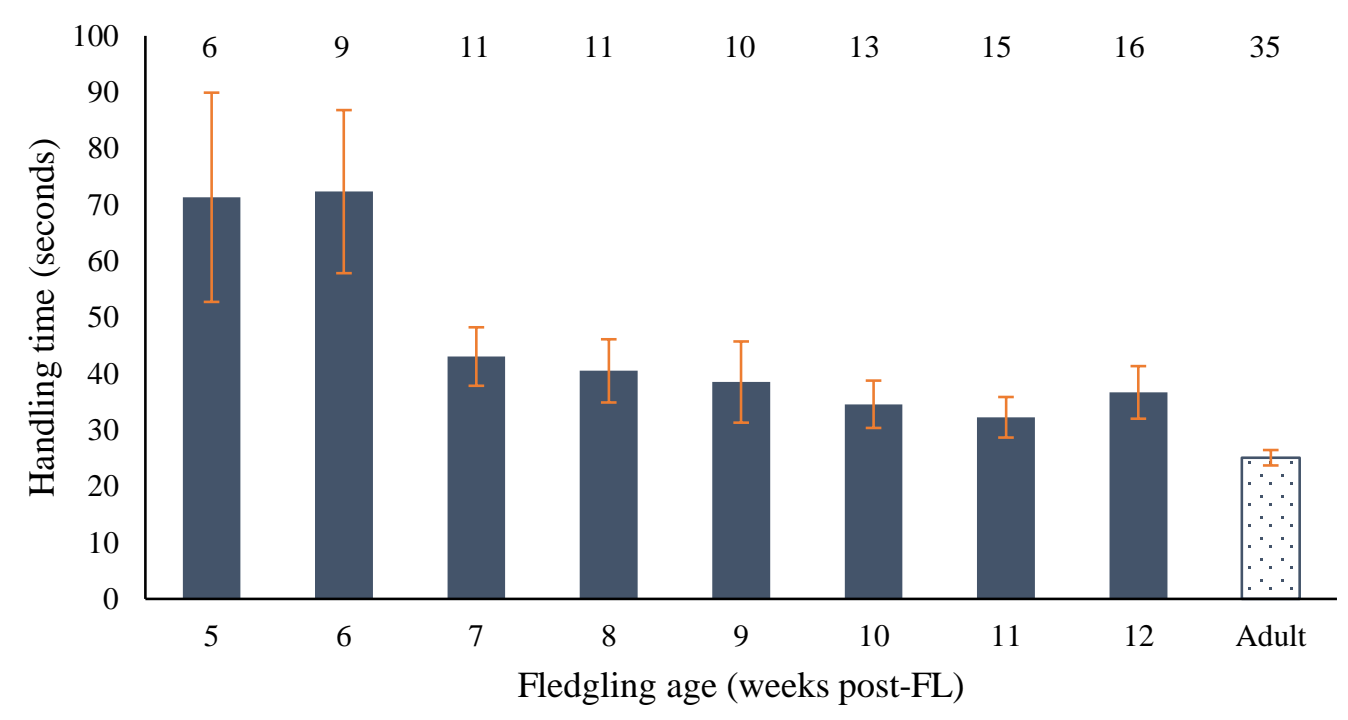

Figure 5. Mean handling time as a function of fledgling age (weeks since fledging) (mean \pm SE). Handling time decreases as fledglings mature with a significant decrease observed at 7 weeks post-fledging. Numbers above bars indicate sample size, i.e. number of fledglings. Error bars represent standard error.

\subsection{Discussion}

The present study examines the development of caching behaviour in a wild passerine, the North Island robin. Based on previous ontogenetic studies of caching birds (Bugnyar et al., 2007; Clayton, 1992, 1994; Haftorn, 1992; Stotz \& Balda, 1995), age was predicted to have a significant effect on caching and its related behaviours, i.e. cache retrieval, number of cache sites used and the time spent handling mealworms prior to caching. Indeed, fledglings increased 
the proportion of mealworms that they cached as they developed, until they were caching at a similar rate to adults. Similarly, handling time gradually decreased with age, but juvenile handling time was still higher than adults by the end of the observation period (12-week postfledge). Cache retrieval appeared synchronously with onset of caching but like site variability, it showed no significant change as juveniles aged. Sexual differences have been reported for adult robins in regards to caching effort and site use (Alexander et al., 2005; Van Horik \& Burns, 2007), however, no such effect was found for juvenile caching rate and site use. Despite the post-fledging care period lasting up to several weeks in NI robins (Armstrong et al., 2000), no effect of parental care environment (caregiver sex or duration of care) was found for caching or it's related behaviours.

The onset of food-caching appears linked to the commencement of independent foraging in the juvenile birds that have been studied to date. Clayton (1992) noted that caching was not observed in hand-reared marsh tits (Poecile palustris) until juveniles began handling small pieces of sunflower seeds (approximately 22 days post-hatch). This result is concordant with observations of wild juvenile willow tits (Poecile montanus) and crested tits (Lophophanes cristatus), who also displayed tentative food-storing behaviour at a similar age (approx. 33 days post-hatch) (Haftorn, 1992). Likewise, the juvenile robins in this study were capable of caching mealworms as early as three weeks post-fledging, however, the majority of subjects began reliably caching from 5 weeks post-fledging. This timeframe (3-5 weeks post-fledging) overlaps with previous reports of the onset for independent foraging in juvenile robins, i.e. approximately four weeks after fledging (Armstrong et al., 2000). Thus, in accordance with previous ontogenetic studies of caching (Bugnyar et al., 2007; Clayton \& Krebs, 1994; Haftorn, 1992; Stotz \& Balda, 1995), there appears to be strong evidence to suggest that caching initially arises instinctively in young robins once they are foraging independently. At this time, juveniles are capable of capturing their own prey but they may also still receive food from their caregivers (pers. obs; Armstrong et al., 2000). As such, they may experience periods of temporary food abundance, a situation which is predicted to induce caching (Vander Wall, 1990).

Following the initial onset of caching, it is likely that experience has a significant role in its development. The present study and other ontogenetic studies quantify experience as fledgling age, i.e. the number of days or weeks since hatching or fledging (Haftorn, 1992; Stotz \& Balda, 1995). A subject's age is thus a numeric representation of the time it has spent interacting with 
its social and natural environment. For juvenile tits of various species, age proves to be significant factor in the development of caching, as demonstrated by the gradual progression from "tentative caching" (where birds deposit and retrieve an item repeatedly before eventually consuming it) to "true caching" (items remain at a site following placement) (Clayton, 1992, 1994; Haftorn, 1992). Likewise in ravens (Corvus corax), the number of food-caching events increased with age, as did the frequency of manipulative elements common in adult caching (i.e. placement, insertion and covering) (Bugnyar et al., 2007). Similarly in this study, juvenile caching effort gradually increased with each week following nest departure. By the end of the observation period (12 weeks post-fledging), juveniles were caching at a rate similar to that observed in adults. Likewise, handling time gradually decreased with age but was still higher than adults at the end of the observation period. These results and those of other ontogenetic studies, suggest that while juveniles are capable of storing excess food at a young age, they are not immediately adept at the behaviour. This is not surprising when one considers that at the onset of caching, juveniles have only just begun to explore and interact with their natural surroundings. For example, at the onset of caching juvenile robins had only left the nest 3-5 weeks prior and during the first two weeks, they are largely immobile and perched high in the canopy (pers. obs.). Thus, with increasing age juveniles are likely to gain foraging and preyhandling experience in addition to a wider understanding of their natural environment. Over time, this accrued experience may facilitate the achievement of adult-like caching behaviour in juveniles.

Some aspects of caching behaviour appear to undergo very little change following their initiation. In this study, cache retrieval rates of juvenile robins remained constant from their onset at 5-weeks post-fledging and were similar to those observed in adults. Clayton (1992) reported a similar result in hand-reared marsh tits; regardless of their previous experience with food items and potential cache sites, the retrieval performance of juvenile marsh tits was significantly better than if the juveniles were searching at random. Clayton concluded that spatial memory, rather than age or experience, was the most influential factor in aiding a subject's relocation of its cached item. Subsequent studies in other caching birds have reported a temporal link between the onset of caching and the acquisition of specific cognitive traits that are vital for cache retrieval, such as the ability to understand that an object can still exist while temporarily out of view (i.e. object permanence) (Bugnyar et al., 2007; Pollok et al., 2000). If, as these studies imply, cognitive traits are essential to the ability to retrieve cached items and these skills emerge simultaneously, then the lack of change in the retrieval rates of juvenile 
robins is not unexpected. If the necessary cognitive skills for cache retrieval are present from the initial onset of caching, cache retrieval behaviour may achieve, little if any, improvement with either experience or age.

Unexpectedly, sex had no significant effect on the caching ability of juvenile robins at any age. This is in contrast to studies of adult robins from the same population which have reported clear differences between the sexes with regards to caching rates and the number of cache sites used, i.e. males have a higher caching rate than females, but user fewer sites in comparison to females (Alexander et al., 2005; Van Horik \& Burns, 2007). The disparity in results might suggest that sexual differences in caching ability are not intrinsically present but are perhaps promoted via social interactions. For instance, Schuett \& Dall (2009) found that in zebra finches (Taeniopygia guttata), the social environment in which subjects were tested contributed to sexual differences in exploration and feeding behaviours. The design of this study was such that juvenile robins were largely observed alone and it was rare that they had to compete with another individual for the food that was offered. If food competition and social interactions promote sexual differences in young birds, then differences might only be observed if juveniles are tested together, or if individuals are tested once they have established their own territories. Either of these situations offer exciting opportunities for future studies of the development of sex differences in caching behaviour.

Corvids, robins and tits do not share a common caching ancestor, yet it appears that they may have similar developmental pathways in terms of caching behaviour. Food-caching is an adaptive response to food scarcity as a result of natural fluctuations in food supply (Vander Wall, 1990). All natural environments experience these fluctuations to one degree or another but certain environments, particularly those in temperate regions, experience these on a much greater scale (Brooke \& Birkhead, 1991). Corvids, robins and tits are three very distinct families however, they all inhabit temperate latitudes and must deal with variable food supplies. This common experience may be one factor which has contributed to similar ontogenetic pathways for caching in these distinct families. A second is their specific foodhandling behaviour. In order for food caching to have evolved, each species must exhibit some genetically controlled trait on which natural selection could act to produce caching behaviour (Vander Wall, 1990). Robins hunt some of the largest invertebrates in the world which must be dismembered before they can be consumed (Higgins \& Peter, 2002; Menzies $\&$ Burns, 2008). Likewise, ravens are opportunistic predators who in many places are 
scavengers, feeding on carcasses that are often quite large (Engel \& Young, 1989; Kristan, Boarman, \& Crayon, 2004). Thus, within both robins and ravens there was a genetic basis on which caching could evolve to be an advantageous foraging strategy. Therefore, the similarities between these different families in the way in which caching develops may be attributed to their similar environmental experiences and food-handling behaviours.

To date, only a few ontogenetic studies of caching behaviour have been performed. These studies have largely been limited to Corvidae and Paridae species in laboratory environments. Similar to other caching birds, the onset of caching in robins appeared at the onset of independent foraging and its development was strongly affected by age and experience. Sex had little influence on any of the caching-related measures examined here, suggesting that the sexual differences that have previously been reported in adult robins in this population (Alexander et al., 2005; Van Horik \& Burns, 2007), arise sometime after the fledging period. Previous studies of caching in adult robins have demonstrated that male and female robins alter their caching and related behaviours in different social contexts (Alexander et al., 2005; Van Horik \& Burns, 2007). As juveniles were mostly observed on their own and interactions with other robins was minimal during observations, examining the ontogeny of caching under different social conditions represents an avenue for future research in this species and others. The ontogenetic similarities between robins and other caching species suggest that these species have undergone shared, convergent pathways in their development of caching behaviour. Thus, in many respects caching behaviour appears to be more similar than different in the birds that exhibit this behaviour. 


\section{Chapter 4: General Discussion}

\subsection{Summary of findings}

The present study set out to examine parental care and the development of caching during the post-fledging period in wild North Island robins (Petroica longipes). In contrast to the period of nestling development, much less is known about parental care of avian young from fledging to independence (Smith, 1978; Weatherhead \& McRae, 1990). This is largely due to increasing difficult with which one can follow and observe interactions between parent and offspring during this period. However, the opposite occurs when studying the North Island robin, an insectivorous New Zealand passerine. Like many birds endemic to isolated islands, robins lack pronounced anti-predator behaviour and will fearlessly approach and interact with humans (Carlquist, 1970; Maloney \& McLean, 1995). Furthermore, robins are highly territorial yearround; thus, individuals can reliably be located during regular monitoring (Higgins \& Peter, 2002). Taken together, these characteristics mean that it becomes increasingly easier to observe interactions between parents and offspring of NI robins, after young have left the nest.

Chapter 2 presents the first detailed examination of brood division in a New Zealand passerine. Brood division describes a form of post-fledging parental care whereby the brood is split between parents, creating matriarchal and patriarchal sub-families which occupy separate areas of a shared breeding territory (McLaughlin \& Montgomerie, 1985; Slagsvold, 1997). This study demonstrated that brood division occurred in most broods which fledged two or more fledglings. Additionally, I showed that an interaction between fledgling sex and size was the basis for these divisions; male fledglings (which were often also larger than their siblings) were typically associated with male parents whereas female (often smaller compared to their siblings) were predominantly cared for by female parents.

Chapter 3 describes the first systematic examination of the ontogeny of food-caching behaviour in a wild passerine. Caching, the handling of food to preserve it for future consumption, occurs in many species worldwide but is rare in animals in the southern hemisphere (Vander Wall, 1990). In this study, I highlighted the influential effect of fledgling age on the development of caching in North Island robins. Juveniles began caching around the time that they began to forage independently ( 4 weeks post-fledging) and their caching rate proceeded to increase over the remainder of the observation period until they were caching at a similar rate to adults. 
The time that was spent handling prey prior to depositing prey at a cache site was also affected by age, decreasing gradually as fledglings aged but was still higher than that observed for adults at the end of the observation period. Other aspects of caching, cache retrieval and the number of different sites used, showed no significant change in either direction following their onset. As previous studies have shown that social environment can influence the hoarding behaviour of other species (Lahti et al., 1998), it is thought that perhaps the lack of differences in these two caching-related behaviours may result from the simplicity of the social environment in which fledglings were observed.

Both brood division and caching are rarely documented amongst species in the southern hemisphere (Lessells, 2002; Vander Wall, 1990). However, my results demonstrate that brood division and caching in North Island robins is similar to what has been observed for other species. For example, broods of NI robins were divided shortly after fledging and on the basis of offspring characteristics. These patterns have been found for numerous birds in a range of environments, e.g. northern temperate (Draganoiu et al., 2005; Wheelwright et al., 2003), equatorial (Tarwater \& Brawn, 2008; Vega et al., 2007) and south temperate (Leedman \& Magrath, 2003). Likewise, caching in juvenile robins arose around the time of independent foraging and gradually increased as juveniles matured. Similar patterns have also been observed for the few studies that have examined the ontogeny of caching in wild and laboratory birds (Bugnyar \& Heinrich, 2005; Clayton, 1992; Haftorn, 1992; Stotz \& Balda, 1995). The similarities with which these behaviours are expressed suggests that brood division and caching behaviour offer same adaptive advantages to species regardless of their geographic location.

Studying brood division and caching in the wild enables examination of how individuals approach the inevitable trade-offs that arise as a result of limited resources. For many animals, parental care hugely beneficial to offspring as it increases their chances of survival through to breed (Clutton-Brock, 1991; Raihani, Nelson-Flower, Moyes, Browning, \& Ridley, 2009; Suzuki, 2010). However, it also imposes costs to the parents because resources invested in a particular offspring, cannot be utilised for other processes (e.g. self-maintenance) or offspring (current or future) (Clutton-Brock, 1991; Goymann, Safari, Muck, \& Schwabl, 2016). Strategies such as brood division provide a unique insight into how birds balance these tradeoffs and maximise their reproductive success. Additionally, there is a trade-off between caching and consumption when a resource is temporarily abundant (Carrascal \& Moreno, 1993). Both are profitable strategies because they allow the "storer" to remove the resources 
from competition and provide energy reserves for periods of food scarcity (Vander Wall, 1990). However, each strategy also has associated costs; for example, in birds consumption may increase their risk of predation if flight is impacted (Witter, 1993). Caching is also risky given the prevalence of cache theft by conspecifics and heterospecifics (Bugnyar \& Heinrich, 2006; Bugnyar \& Kotrschal, 2002; Hitchcock \& Sherry, 1995; Shaw \& Clayton, 2013; Steer \& Van Horik, 2006). By identifying what factors influence such decisions around maximising use of available resources, we may be better able to understand offspring survival in the wild.

\subsection{Future directions}

Previous caching studies have demonstrated that caching and its related behaviours can vary in different social environments (Alexander et al., 2005; Bugnyar \& Heinrich, 2006; Kalinowski, Gabriel, \& Black, 2015; Van Horik \& Burns, 2007). For instance, adult robins from the same population as this study, have been shown to dramatically decrease their caching rates in the presence of their mate compared to when they are alone (Burns \& Steer, 2006). Likewise, the presence of a competitor at a feeder was found to promote caching in pinyon jays (Gymnorhinus cyanocephalus) (Bednekoff \& Balda, 1996). The design of this study was such that juveniles were observed in a relatively simple social environment, i.e. they were largely alone and rarely had to compete with another individual for the food that was offered. Thus, future studies could explore the role of social context in the ontogeny of caching. In North Island robins, this could be achieved by observing juveniles together (e.g. siblings or fledglings in neighbouring territories) or by observing juveniles in their newly established territories shortly after natal dispersal. Such studies may offer new insights into how food competition and social interaction influence the development of caching behaviour.

Environmental factors, such as food availability, have been proposed to influence brood division. A study of two species of Darwin's finches (Geospiza fortis and G. scandens) over several years, found that brood division rarely occurred in years where food was abundant (Price \& Gibbs, 1987). Similarly results have also been reported for the European robin (Erithacus rubecula) (Harper, 1985) and the American robin (Turdus migratorius), (Slagsvold, 1997). Additionally, when brood division does occur during times of food scarcity, parents are thought to adjust their feeding behaviour and bias their feeds towards the most valuable offspring (Slagsvold, 1997). Thus, different environmental contexts may cause parents to 
adjust the way in which they perform this behaviour or brood division may no longer be a beneficial strategy for parents.

\subsection{Conclusion}

The two studies described in this dissertation examine behaviours that have either been previously difficult to document in the wild or have not been documented in this species. Overall, the results highlight the behavioural similarities between the North Island robin and other avian species exhibiting brood division and caching. Additionally, they also demonstrate the suitability of the North Island robin for future behavioural research given the ease with which these birds can be observed in the wild. 


\section{References}

Alexander, L., Duthie, C., Fyfe, J., Haws, Z., Hunt, S., Montoya, I., ... Burns, K. C. (2005). An experimental evaluation of food hoarding by North Island robins (Petroica australis longipes). Notornis, 52(3), 138-142.

Anthonisen, K., Krokene, C., \& Lifjeld, J. (1997). Brood division is associated with fledgling dispersion in the bluthroat. The American Ornithologists' Union, 114(4), 553-561.

Armstrong, D. P., Ewen, J. G., Dimond, W. J., Lovegrove, T. G., Bergstrom, a., \& Walter, B. (2000). Breeding biology of North Island robins (Petroica australis longipes) on Tiritiri Matangi Island, Hauraki Gulf, New Zealand. Notornis, 47(2), 106-118.

Aroyo, B. E., De Cornulier, T., \& Bretagnolle, V. (2002). Parental investment and parentoffspring conflicts during the postfledging period in Montagu's harriers. Animal Behavior, 63, 235-244.

Balda, R. P., \& Kamil, A. C. (1992). Long-term spatial memory in Clark's nutcracker, Nucifraga columbiana. Animal Behavior, 44(4), 761-769.

Bateman, A. J. (1948). Intra-sexual selection in Drosophila. Heredity, 2, 349-368.

Bednekoff, P. A., \& Balda, R. P. (1996). Social Caching and Observational Spatial Memory in Pinyon Jays. Behaviour, 133(11/12), 807-826.

Birkhead, T. R., \& Møller, A. P. (1995). Extra-pair copulation and extra-pair paternity in birds. Animal Behaviour, 49(3), 843-848. http://doi.org/10.1016/0003-3472(95)80217-7

Bossema, I. (1979). Jays and Oaks : An Eco-Ethological Study of a Symbiosis. Behaviour, $70(1), 1-117$.

Boulton, R. L., Richard, Y., \& Armstrong, D. P. (2010). The Effect of Male Incubation Feeding, Food and Temperature on the Incubation Behaviour of New Zealand Robins. Ethology, 116(6), 490-497. http://doi.org/10.1111/j.1439-0310.2010.01759.x

Brodin, A. (2010). The history of scatter hoarding studies. Philosophical Transactions of the Royal Society B: Biological Sciences, 365(1542), 869-881. http://doi.org/10.1098/rstb.2009.0217

Brooke, M., \& Birkhead, T. (1991). The Cambridge encyclopedia of ornithology. Cambridge: Cambridge University Press.

Budden, A. E., \& Beissinger, S. R. (2009). Resource allocation varies with parental sex and brood size in the asynchronously hatching green-rumped parrotlet (Forpus passerinus). Behavioral Ecology and Sociobiology, 63, 637-647. http://doi.org/10.1007/s00265-0080698-X

Bugnyar, T., \& Heinrich, B. (2005). Ravens, Corvus corax, differentiate between knowledgeable and ignorant competitors. Proceedings of the Royal Society B:

Biological Sciences, 272(1573), 1641-1646. http://doi.org/10.1098/rspb.2005.3144

Bugnyar, T., \& Heinrich, B. (2006). Pilfering ravens, Corvus corax, adjust their behaviour to social context and identity of competitors. Animal Cognition, 9(4), 369-376. http://doi.org/10.1007/s10071-006-0035-6

Bugnyar, T., \& Kotrschal, K. (2002). Observational learning and the raiding of food caches in ravens, Corvus corax: is it "tactical" deception? Animal Behaviour, 64(2), 185-195. http://doi.org/10.1006/anbe.2002.3056

Bugnyar, T., Stöwe, M., \& Heinrich, B. (2007). The ontogeny of caching in ravens, Corvus corax. Animal Behaviour, 74(4), 757-767. http://doi.org/10.1016/j.anbehav.2006.08.019

Burns, K. . (2009). Fine-scale food hoarding decisions in New Zealand Robins (Petroica australis): Is inter-sexual competition important? Journal of Ornithology, 150(2), 321328. http://doi.org/10.1007/s10336-008-0355-1 
Burns, K. C., \& Steer, J. (2006). Dominance rank influences food hoarding in New Zealand Robins Petroica australis. Ibis, 148, 266-272. http://doi.org/10.1111/j.1474919X.2006.00529.x

Burns, K. C., \& Van Horik, J. (2007). Sexual differences in food re-caching by New Zealand robins Petroica australis. Journal of Avian Biology, 38(3), 394-398. http://doi.org/10.1111/j.2007.0908-8857.03864.x

Bustamante, J. (1993). Post-fledging dependence period and development of flight and hunting behaviour in the Red Kite Milvus milvus. Bird Study, 40(December), 181-188. http://doi.org/10.1080/00063659309477181

Byle, P. a F. (1990). Brood Division and Parental Care in the Period between Fledging and Independence in the Dunnock (Prunella modularis). Behaviour, 113(1/2), 1-20. Retrieved from http://www.jstor.org/stable/4534847

Cameron-MacMillan, M. L., Walsh, C. J., Wilhelm, S. I., \& Storey, A. E. (2007). Male chicks are more costly to rear than females in a monogamous seabird, the Common Murre. Behavioral Ecology, 18(1), 81-85.

Carlquist, S. (1970). Hawaii: a Natural History. Honolulu: Natural History Press.

Carrascal, L. M., \& Moreno, E. (1993). Food caching versus immediate consumption in the nuthatch: the effect of social-context. Ardea, 0081 N2(March), 135-141.

Clark, A. B. (1978). Sex ratio and local resource competition in a prosimian primate. Science, 201, 163-165.

Clarkson, K., Eden, S. F., Sutherland, W. J., \& Houston, A. I. (1986). Density dependence and magpie food hoarding. Journal of Animal Ecology, 55, 111-121.

Clayton, N. S. (1992). The ontogeny of food-storing and retrieval in Marsh tits. Behaviour, 122(1-2), 11-25. http://doi.org/10.1017/CBO9781107415324.004

Clayton, N. S. (1994). The role of age and experience in the behavioural development of food-storing and retrieval in marsh tits, Parus palustris. Animal Behavior, 47(6), 14351444.

Clayton, N. S., Dally, J. M., \& Emery, N. J. (2007). Social cognition by food-caching corvids. The western scrub-jay as a natural psychologist. Philosophical Transactions of the Royal Society of London. Series B, Biological Sciences, 362(1480), 507-522. http://doi.org/10.1098/rstb.2006.1992

Clayton, N. S., \& Krebs, J. R. (1994). Memory for spatial and object-specific cues in foodstoring and non-storing birds. Journal of Comparative Physiology A, 174(3), 371-379. http://doi.org/10.1007/BF00240218

Clutton-Brock, T. H. (1991). The Evolution of Parental Care. Princeton: Princeton University Press.

Cockburn, A. (2006). Prevalence of different modes of parental care in birds. Proceedings of the Royal Society B: Biological Sciences, 273, 1375-1383. http://doi.org/10.1098/rspb.2005.3458

Cox, W. A., Thompson, F. R., Cox, A. S., \& Faaborg, J. (2014). Post-fledging survival in passerine birds and the value of post-fledging studies to conservation. Journal of Wildlife Management, 78(2), 183-193. http://doi.org/10.1002/jwmg.670

Davison, G. (1992). Brood division and sibling relationships in captive crested wood partridges (Rollulus rouloul). Gibier Faune Sauvage, 9, 719-728. http://doi.org/10.1055/s-2004-815600

Draganoiu, T., Nagle, L., Musseau, R., \& Kreutzer, M. (2005). Parental care and brood division in a songbird, the black redstart. Behaviour, 142(11), 1495-1514. http://doi.org/10.1163/156853905774831828

Edwards, P. J. (1985). Brood division and transition to independence in Blackbirds Turdus merula. Ibis, 127(1), 42-59. http://doi.org/10.1111/j.1474-919X.1985.tb05036.x 
Engel, K. A., \& Young, L. S. (1989). Spatial and temporal patterns in the diet of Common Ravens in southwestern Idaho. Condor, 372-378.

Forstmeier, W., \& Schielzeth, H. (2011). Cryptic multiple hypotheses testing in linear models: Overestimated effect sizes and the winner's curse. Behavioral Ecology and Sociobiology, 65(1), 47-55. http://doi.org/10.1007/s00265-010-1038-5

Freeman-Gallant, C. R., \& Rothstein, M. D. (1999). Apparent Heritability of Parental Care in Savannah Sparrows. The Auk, 116(4), 1132-1136.

Gerber, L. R., Reichman, O. J., \& Roughgarden, J. (2004). Food hoarding: future value in optimal foraging decisions. Ecological Modelling, 175(1), 77-85.

http://doi.org/10.1016/j.ecolmodel.2003.10.022

Gottlander, K. (1987). Parental feeding behaviour and sibling competition in the pied flycatcher Ficedula hypoleuca. Ornis Scandinavica, 18, 269-279.

Gowaty, P. A. (1983). Male Parental Care and Apparent Monogamy Among Eastern Bluebirds (Sialia sialis). The American Naturalist, 121(2), 149-157.

Gowaty, P. A., \& Droge, D. L. (1991). Sex-ratio conflict and the evolution of sex-biased provisioning in birds. Proceedings of the International Ornithological Congress, 20, 932-945.

Goymann, W., Safari, I., Muck, C., \& Schwabl, I. (2016). Sex roles, parental care and offspring growth in two contrasting coucal species. Royal Society Open Science, 3, 1335-1353. http://doi.org/10.1111/jeb.12657

Green, D. J., \& Cockburn, A. (2001). Post-fledging care, philopatry and recruitment in brown thornbills. Journal of Animal Ecology, 70(3), 505-514. http://doi.org/10.1046/j.13652656.2001.00503.x

Greenwood, P. J. (1980). Mating systems, philopatry and dispersal in birds and mammals. Animal Behavior, 28, 1140-1162.

Guo, H., Cao, L., Peng, L., Zhao, G., \& Tang, S. (2010). Parental Care, Development of Foraging Skills, and Transition to Independence in the Red-Footed Booby. The Condor, 112(1), 38-47. http://doi.org/10.1525/cond.2010.090154

Haftorn, S. (1992). Ontogeny of food storing in titmice Parus spp. Ibis, 134, 69-71.

Harper, D. G. C. (1985). Brood division in robins. Animal Behavior, 33, 466-480.

Heather, B. D., \& Robertson, H. A. (2005). The Field Guide to the Birds of New Zealand. Auckland: Penguin Books.

Heinsohn, R. G. (1991). Slow Learning of Foraging Skills and Extended Parental Care in Cooperatively Breeding White-Winged Choughs. The American Naturalist, 137(6), 864-881.

Higgins, P., \& Peter, J. (2002). Petroica australis, New Zealand Robin. In P. Higgins \& J. Peters (Eds.), Handbook of Australian, New Zealand and Antarctic Birds, Vol. 6: Pardalotes to Shrike. Oxford: Oxford University Press.

Hitchcock, C. L., \& Sherry, D. F. (1995). Cache Pilfering and Its Prevention in Pairs of Black-Capped Chickadees Cache pilfering and its prevention in pairs of Black-capped Chickadees. Journal of Avian Biology, 26(3), 187-192. http://doi.org/10.2307/3677318

Jacobs, L. F., \& Liman, E. R. (1991). Grey squirrels remember the locations of buried nuts. Animal Behavior, 41, 103-110.

Kalinowski, R. S., Gabriel, P. O., \& Black, J. M. (2015). Who's watching influences caching effort in wild Steller's jays (Cyanocitta stelleri). Animal Cognition, 18(1), 95-98. http://doi.org/10.1007/s10071-014-0780-x

Kallander, H. (2007). Food hoarding and use of stored food by Rooks Corvus frugilegus. Bird Study, 54(December), 192-198. http://doi.org/Animal sciences

Kopachena, J. G., \& Falls, J. B. (1991). An experimental study of brood division in whitethroated sparrows. Animal Behaviour, 42(3), 395-402. http://doi.org/10.1016/S0003- 
3472(05)80038-7

Korpimaki, E. (1987). Prey caching of breeding Tengmalm's owls Aegolius funereus as a buffer against temporary food shortage. Ibis, 129(4), 499-510. http://doi.org/10.1111/j.1474-919X.1987.tb08237.x

Kristan, W. B., Boarman, W. I., \& Crayon, J. J. (2004). Diet composition of common ravens across the urban-wildland interface of the West Mojave Desert. Wildlife Society Bulletin, 32(1), 244-253.

Kross, S. M., \& Nelson, X. J. (2012). Factors influencing the behavioural development of juvenile New Zealand Falcons. Emu, 113(1), 84-87.

Lahti, K., Koivula, K., Rytkoenen, S., Mustonen, T., Welling, P., Pravosudov, V. V, \& Orell, M. (1998). Social influences on food caching in willow tits: a field experiment. Behav.Ecol., 9(2), 122-129. http://doi.org/10.1093/beheco/9.2.122

Langen, T. A. (2000). Prolonged offspring dependence and cooperative breeding in birds. Behavioral Ecology, 11(4), 367-377. http://doi.org/10.1093/beheco/11.4.367

Leedman, A. W., \& Magrath, R. D. (2003). Long-term brood division and exclusive parental care in a cooperatively breeding passerine. Animal Behaviour, 65(6), 1093-1108. http://doi.org/10.1006/anbe.2003.2164

Lessells, C. M. (2002). Parentally biased favouritism: why should parents specialize in caring for different offspring? Philosophical Transactions of the Royal Society of London. Series B, Biological Sciences, 357(1419), 381-403. http://doi.org/10.1098/rstb.2001.0928

Linkhart, B., \& Reynolds, R. (1987). Brood Division and Postnesting Behavior of Flammulated Owls. Wilson Bulletin, 99(2), 240-243.

Male, L. H., \& Smulders, T. V. (2007). Hyperdispersed cache distributions reduce pilferage: a field study. Animal Behavior, 73, 717-726.

Male, L. H., \& Smulders, T. V. (2008). Hyperdispersed cache distributions reduce pilferage: a laboratory study. Journal of Avian Biology, 39, 170-177. http://doi.org/10.1111/j.2008.0908-8857.04019.x

Maloney, R., \& McLean, I. (1995). Historical and experimental learned predator recognition in free-living New-Zealand robins. Animal Behaviour, 50(5), 1193-1201. http://doi.org/10.1016/0003-3472(95)80036-0

McGavin, S. (2009). Density and pair fidelity in a translocated population of north island robin (petroica longipes). Notornis, 56(4), 206-212.

McLaughlin, R. L., \& Montgomerie, R. D. (1985). Brood Division by Lapland Longspurs. The Auk, 102(4), 687-695.

McRae, S. B., Weatherhead, P. J., \& Montgomerie, R. (1993). American Robin Nestlings Compete by Jockeying for Position. Behavioral Ecology and Sociobiology, 33(2), 101106.

Menzies, I. J., \& Burns, K. C. (2008). Food Hoarding in the New Zealand Robin: A Review and Synthesis. In Animal Behaviour: New Research (pp. 1-21).

Moreno, J. (1984). Parental Care of Fledged Young, Division of Labor, and the Development of Foraging Techniques in the Northern Wheatear (Oenanthe oenanthe L.). The Auk, 101(4), 741-752. Retrieved from http://www.jstor.org/stable/4086901

Mundry, R., \& Fischer, J. (1998). Use of statistical programs for non parametric tests of small samples often leads to incorrect $\mathrm{P}$ values: examples from Animal Behaviour. Animal Behaviour, 56(1), 256-259.

Piaget, J. (1937). La construction du Réel Chez L'Enfant. Neuchâtel: Delachaux \& Niestlé Translated by M. Cook as The Construction of Reality in the Child. New York: Basic Books.

Pollok, B., Prior, H., \& Güntürkün, O. (2000). Development of object permanence in food- 
storing magpies (Pica pica). Journal of Comparative Psychology, 114(2), 148-157. http://doi.org/10.1037/0735-7036.114.2.148

Powlesland, R. G. (1980). Food-storing behaviour of the South Island robin. Mauri Ora, 8 , $11-20$.

Powlesland, R. G. (1983). Breeding and Mortality of the South Island robin in Kowhai Bush, Kaikoura. Notornis, 30(4), 265-283.

Powlesland, R. G., Knegtmans, J. W., \& Marshall, I. S. J. (2000). Breeding biology of North Island robins (Petroica australis longipes) in Pureora Forest Park. Notornis, 47(2), 97105.

Price, T. D., \& Gibbs, H. L. (1987). Brood division in Darwin's Ground Finches. Animal Behavior, 35(1), 299-301.

Raihani, N. J., Nelson-Flower, M. J., Moyes, K., Browning, L. E., \& Ridley, A. R. (2009). Synchronous provisioning increases brood survival in cooperatively breeding pied babblers. Journal of Animal Ecology, 79(1), 44-52.

Ridley, A. R., \& Raihani, N. J. (2007). Variable postfledging care in a cooperative bird: Causes and consequences. Behavioral Ecology, 18(6), 994-1000. http://doi.org/10.1093/beheco/arm074

Royle, N. J., Smiseth, P. T., \& Kolliker, M. (2012). The Evolution of Parental Care. Oxford: Oxford University Press.

Russell, E. M. (2000). Avian life histories: Is extended parental care the southern secret? Emu, 100(5 SUPPL.), 377-399. http://doi.org/10.1071/MU0005S

Russell, E. M., Yom-Tov, Y., \& Geffen, E. (2004). Extended parental care and delayed dispersal: Northern, tropical, and southern passerines compared. Behavioral Ecology, 15(5), 831-838. http://doi.org/10.1093/beheco/arh088

Salwiczek, L. H., Emery, N. J., Schlinger, B., \& Clayton, N. S. (2009). The development of caching and object permanence in Western scrub-jays (Aphelocoma californica): which emerges first? Journal of Comparative Psychology, 123(3), 295-303. http://doi.org/10.1037/a0016303

Schuett, W., \& Dall, S. R. X. (2009). Sex differences, social context and personality in zebra finches, Taeniopygia guttata. Animal Behaviour, 77(5), 1041-1050.

http://doi.org/10.1016/j.anbehav.2008.12.024

Shaw, R. C., Boogert, N. J., Clayton, N. S., \& Burns, K. C. (2015). Wild psychometrics: evidence for "general" cognitive performance in wild New Zealand robins, Petroica longipes. Animal Behaviour, 109, 101-111. http://doi.org/10.1016/j.anbehav.2015.08.001

Shaw, R. C., \& Clayton, N. S. (2013). Careful cachers and prying pilferers: Eurasian jays (Garrulus glandarius) limit auditory information available to competitors. Proceedings. Biological Sciences / The Royal Society, 280(1752), 20122238. http://doi.org/10.1098/rspb.2012.2238

Shiao, M.-T., Chuang, M.-C., \& Wang, Y. (2009). Differential Food Distribution by Male and Female Green-backed Tits (Parus monticolus) in Relation to Nestling Size. The Auk, 126(4), 906-914. http://doi.org/10.1525/auk.2009.08205

Slagsvold, T. (1997). Brood division in birds in relation to offspring size: sibling rivalry and parental control. Animal Behaviour, 54(6), 1357-68. http://doi.org/10.1006/anbe.1997.0530

Slagsvold, T., Amundsen, T., \& Dale, S. (1994). Selection by sexual conflict for evenly spaced offspring in blue tits. Nature, 370, 136-138.

Small, D. R. (2004). Survival, Breeding Success and Habitat Selection of North Island Robins (Petroica australis longipes) Translocated to the Karori Wildlife Sanctuary. Victoria University of Wellington. 
Smith, J. N. M. (1978). Division of labour by song sparrows feeding fledged young. Canadian Journal of Zoology, 56, 187-191.

Soper, M. F. (1963). New Zealand Bird Portraits. Auckland: Whitcombe and Tombs.

Stamps, J. (1990). When should avian parents differentially provision sons and daughters? Naturalist, 135, 671-685.

Steer, J., \& Van Horik, J. (2006). North Island robin (Petroica australis longipes) food caches are stolen by stitchbirds (Notiomystis cincta) and bellbirds (Anthornis melanura). Notornis, 53(3), 315-316.

Stotz, N. G., \& Balda, R. P. (1995). Cache and recovery behavior of wild pinyon jays in northern Arizona. Southwestern Association of Naturalists, 40(2), 180-184.

Suzuki, S. (2010). Progressive provisioning by the females of the earwig, Anisolabis maritima, increases the survival rate of the young. Journal of Insect Science, 10(1), 184.

Tanner, M., Kölliker, M., \& Richner, H. (2008). Differential food allocation by male and female great tit, Parus major, parents: are parents or offspring in control? Animal Behaviour, 75(4), 1563-1569. http://doi.org/10.1016/j.anbehav.2007.10.010

Tarwater, C. E., \& Brawn, J. D. (2008). Patterns of brood division and an absence of behavioral plasticity in a neotropical passerine. Behavioral Ecology and Sociobiology, 62(9), 1441-1452. http://doi.org/10.1007/s00265-008-0574-8

Trivers, R. L. (1972). Parental investment and Sexual Selection. In B. Campbell (Ed.), Sexual Selection and the Descent of Man (pp. 136-179). Chicago: Aldine Publishing Company.

Trivers, R. L. (1974). Parent-Offspring Conflict. American Zoologist, 14(1), 249-264. Retrieved from http://www.jstor.org/stable/3881986

Van Horik, J., \& Burns, K. (2007). Cache spacing patterns and reciprocal cache theft in New Zealand robins. Animal Behaviour, 73(6), 1043-1049. http://doi.org/10.1016/j.anbehav.2006.07.014

Vander Wall, S. B. (1990). Food hoarding in animals. Chicago: The University of Chicago Press.

Vander Wall, S. B., \& Balda, R. P. (1981). Ecology and evolution of food-storage behavior in conifer-seed-caching corvids. Zeitschrift Fur Tierpsychologie, 56, 217-242.

Vega, L. B., Holloway, G. J., Millett, J. E., \& Richardson, D. S. (2007). Extreme genderbased post-fledging brood division in the toc-toc. Behavioral Ecology, 18(4), 730-735. http://doi.org/10.1093/beheco/arm038

Vega Rivera, J. H., Haas, C. A., Rappole, J. H., \& McShea, W. J. (2000). Parental care of fledglings wood thrushes. The Wilson Bulletin, 112(2), 233-237.

Verhulst, S., \& Hut, R. a. (1996). Post-fledging care, multiple breeding and the costs of reproduction in the great tit. Animal Behaviour, 51(5), 957-966. http://doi.org/10.1006/anbe.1996.0099

Weatherhead, P. J., \& McRae, S. B. (1990). Brood care in American robins: Implications for mixed reproductive strategies by females. Animal Behaviour, 39(6), 1179-1188. http://doi.org/10.1016/S0003-3472(05)80790-0

Weathers, W. W., \& Sullivan, K. A. (1989). Juvenile foraging proficiency, parental effort, and avian re- productive success. Ecological Monographs, 59, 223-246.

Weathers, W. W., \& Sullivan, K. A. (1991). Foraging efficiency of parent juncos and their young. Condor, 93(2), 346-353.

Westneat, D. F., Clark, A. B., \& Rambo, K. C. (1995). Within-Brood Patterns of Paternity and Paternal Behavior in Red-Winged Blackbirds. Behavioral Ecology and Sociobiology, 37(5), 349-356.

Wheelwright, N. T., \& Mauck, R. A. (1998). Philopatry, natal dispersal and inbreeding avoidance in an island population of Savannah sparrows. Ecology, 79, 755-767.

Wheelwright, N. T., \& Templeton, J. J. (2003). Development of foraging skills and the 
Transition to independence in juvenile Savannah Sparrows. The Condor, 105, 279-287. Wheelwright, N., Tice, K., \& Freeman-Gallant, C. (2003). Postfledging parental care in Savannah sparrows: sex, size and survival. Animal Behaviour, 65(3), 435-443. http://doi.org/10.1006/anbe.2003.2086

Witter, M. S. (1993). The Ecological Costs of Avian Fat Storage. Philosophical Transactions: Biological Sciences, 340, 73-92.

Woodard, J. D., \& Murphy, M. T. (1999). Sex roles, parental experience and reproductive success of eastern kingbirds, Tyrannus tyrannus. Animal Behaviour, 57, 105-115. http://doi.org/10.1006/anbe.1998.0998 


\section{Appendices}

Appendix 1. Distribution of parental feeds to single-fledgling broods. Only broods where $>5$ feeding events were observed are considered. ' $\mathrm{M}$ ' denotes males, ' $\mathrm{F}$ ' females, 'B' biparental care. Significant codes: ‘***' 0.001, ' $* *$ ' 0.01, ' $*$ ’ 0.05, ' + ' 0.1, ' ++ ' 1 .

\begin{tabular}{cccccc}
\hline & \multicolumn{2}{c}{ Parental feeding } & & & \\
\cline { 2 - 3 } visits & & & \\
\cline { 2 - 3 } & Male & Female & & Fledgling sex & Caregiver sex \\
\hline 1 & 16 & 0 & $* * *$ & $\mathrm{M}$ & $\mathrm{M}$ \\
2 & 14 & 0 & $* * *$ & $\mathrm{M}$ & $\mathrm{M}$ \\
17 & 32 & 0 & $* * *$ & $\mathrm{~F}$ & $\mathrm{M}$ \\
20 & 28 & 4 & $* * *$ & $\mathrm{M}$ & $\mathrm{M}$ \\
22 & 12 & 1 & $* *$ & $\mathrm{~F}$ & $\mathrm{M}$ \\
35 & 10 & 0 & $* *$ & $\mathrm{~F}$ & $\mathrm{M}$ \\
40 & 4 & 2 & ++ & $\mathrm{F}$ & $\mathrm{B}$ \\
46 & 42 & 0 & $* * *$ & $\mathrm{M}$ & $\mathrm{M}$ \\
58 & 5 & 10 & ++ & $\mathrm{F}$ & $\mathrm{B}$ \\
70 & 4 & 3 & ++ & $\mathrm{M}$ & $\mathrm{B}$ \\
73 & 6 & 4 & ++ & $\mathrm{F}$ & $\mathrm{B}$ \\
85 & 19 & 1 & $* * *$ & $\mathrm{M}$ & $\mathrm{M}$ \\
86 & 34 & 1 & $* * *$ & $\mathrm{~F}$ & $\mathrm{M}$ \\
84 & 9 & 0 & $* *$ & $\mathrm{M}$ & $\mathrm{M}$ \\
91 & 2 & 12 & $*$ & $\mathrm{~F}$ & $\mathrm{~F}$ \\
101 & 0 & 32 & $* * *$ & $\mathrm{~F}$ & $\mathrm{~F}$ \\
\hline
\end{tabular}


Appendix 2. Distribution of parental feeds among broods of two or more fledglings. For offspring banded after fledging, only feeding events recorded thereafter are considered. Brood division types: ' $C$ ' complete division, ' $P$ ' partial division, ' $U$ ' unknown due to insufficient observations. For all comparisons, $d f=1$ except for brood 49 and 64 where $d f=$ 2. Significant codes: '***' 0.001, ' $* *$ ' 0.01, ' $*$ ' 0.05, ' + ' 0.1, ' ++ ' 1 .

\begin{tabular}{|c|c|c|c|c|c|c|c|c|}
\hline \multirow[b]{2}{*}{ Brood } & \multirow[b]{2}{*}{ Parent } & \multicolumn{3}{|c|}{ Observed } & \multirow[b]{2}{*}{ Expected } & \multirow[b]{2}{*}{$\chi^{2}$} & \multirow[b]{2}{*}{$p$} & \multirow[b]{2}{*}{ BD type } \\
\hline & & FL 1 & FL 2 & FL 3 & & & & \\
\hline \multirow[t]{2}{*}{1} & $\mathrm{M}$ & 1 & 32 & - & 16.5 & 16.349 & $* * *$ & $\mathrm{C}$ \\
\hline & $\mathrm{F}$ & 32 & 2 & - & 17 & 14.316 & $* * *$ & \\
\hline \multirow[t]{2}{*}{4} & M & 13 & 0 & - & 6.5 & 6.2051 & $*$ & $\mathrm{P}$ \\
\hline & $\mathrm{F}$ & 0 & 1 & - & 0.5 & 0 & ++ & \\
\hline \multirow[t]{2}{*}{5} & M & 2 & 5 & - & 3.5 & 0.074866 & ++ & $\mathrm{P}$ \\
\hline & F & 22 & 2 & - & 12 & 8.1681 & $* *$ & \\
\hline \multirow[t]{2}{*}{6} & M & 0 & 8 & - & 4 & 3 & + & $\mathrm{P}$ \\
\hline & $\mathrm{F}$ & 10 & 0 & - & 5 & 4.2667 & $*$ & \\
\hline \multirow[t]{2}{*}{8} & M & 34 & 0 & - & 17 & 20.078 & $* * *$ & $\mathrm{C}$ \\
\hline & $\mathrm{F}$ & 0 & 35 & - & 17.5 & 20.743 & $* * *$ & \\
\hline \multirow[t]{2}{*}{9} & M & 15 & 0 & - & 7.5 & 7.5111 & $* *$ & $\mathrm{C}$ \\
\hline & $\mathrm{F}$ & 1 & 21 & - & 11 & 9.2812 & $* *$ & \\
\hline \multirow[t]{2}{*}{10} & $\mathrm{M}$ & 1 & 0 & - & 0.5 & 0 & ++ & $\mathrm{U}$ \\
\hline & F & 0 & 2 & - & 1 & 0 & ++ & \\
\hline \multirow[t]{2}{*}{11} & M & 0 & 16 & - & 8 & 8.1667 & $* *$ & $\mathrm{P}$ \\
\hline & F & 6 & 0 & - & 3 & 1.7778 & ++ & \\
\hline \multirow[t]{2}{*}{13} & M & 0 & 7 & - & 3.5 & 2.381 & ++ & $\mathrm{P}$ \\
\hline & $\mathrm{F}$ & 22 & 0 & - & 11 & 12.121 & $* * *$ & \\
\hline \multirow[t]{2}{*}{14} & $\mathrm{M}$ & 4 & 45 & - & 24.5 & 18.813 & $* * *$ & $\mathrm{C}$ \\
\hline & $\mathrm{F}$ & 39 & 0 & - & 19.5 & 23.402 & $* * *$ & \\
\hline \multirow[t]{2}{*}{15} & M & 6 & 1 & - & 3.5 & 0.73684 & ++ & $\mathrm{P}$ \\
\hline & $\mathrm{F}$ & 21 & 1 & - & 11 & 9.2812 & $* *$ & \\
\hline \multirow[t]{2}{*}{16} & $\mathrm{M}$ & 1 & 17 & - & 9 & 6.7846 & $* *$ & $\mathrm{C}$ \\
\hline & $\mathrm{F}$ & 23 & 0 & - & 11.5 & 12.783 & $* * *$ & \\
\hline \multirow[t]{2}{*}{17} & $\mathrm{M}$ & 9 & 3 & - & 6 & 0.71111 & ++ & $\mathrm{U}$ \\
\hline & F & 0 & 4 & - & 2 & 0.6667 & ++ & \\
\hline \multirow[t]{2}{*}{19} & $\mathrm{M}$ & 41 & 0 & - & 20.5 & 24.732 & $* * *$ & $\mathrm{C}$ \\
\hline & $\mathrm{F}$ & 0 & 41 & - & 20.5 & 24.732 & $* * *$ & \\
\hline \multirow[t]{2}{*}{20} & M & 12 & 0 & - & 6 & 5.5556 & $*$ & $\mathrm{P}$ \\
\hline & $\mathrm{F}$ & 0 & 2 & - & 1 & 0 & ++ & \\
\hline \multirow[t]{2}{*}{21} & M & 1 & 17 & - & 9 & 6.7846 & $* *$ & $\mathrm{P}$ \\
\hline & $\mathrm{F}$ & 8 & 3 & - & 5.5 & 0.43137 & ++ & \\
\hline 25 & $\mathrm{M}$ & 0 & 0 & - & NA & NA & NA & $\mathrm{U}$ \\
\hline & $\mathrm{F}$ & 10 & 12 & - & 0 & 1 & ++ & \\
\hline 30 & $\mathrm{M}$ & 15 & 0 & - & 7.5 & 7.5111 & $* *$ & $\mathrm{C}$ \\
\hline & F & 5 & 14 & - & 9.5 & 1.3661 & ++ & \\
\hline 31 & $\mathrm{M}$ & 2 & 35 & - & 18.5 & 16.21 & $* * *$ & $\mathrm{C}$ \\
\hline & $\mathrm{F}$ & 23 & 5 & - & 14 & 5.0982 & $*$ & \\
\hline 32 & M & 4 & 28 & - & 16 & 8.8 & $* *$ & $\mathrm{C}$ \\
\hline & $\mathrm{F}$ & 19 & 3 & - & 11 & 5.1333 & $*$ & \\
\hline 34 & M & 4 & 0 & - & 2 & 0.66667 & ++ & $\mathrm{U}$ \\
\hline & $\mathrm{F}$ & 17 & 21 & - & 19 & 0.052778 & ++ & \\
\hline
\end{tabular}




\begin{tabular}{|c|c|c|c|c|c|c|c|c|}
\hline \multirow[t]{2}{*}{36} & $\mathrm{M}$ & 0 & 8 & - & 4 & 3 & + & $\mathrm{P}$ \\
\hline & $\mathrm{F}$ & 19 & 0 & - & 9.5 & 10.14 & $* *$ & \\
\hline \multirow[t]{2}{*}{37} & $\mathrm{M}$ & 0 & 0 & - & NA & NA & NA & $\mathrm{U}$ \\
\hline & $\mathrm{F}$ & 3 & 2 & - & 2.5 & 0 & ++ & \\
\hline \multirow[t]{2}{*}{38} & $\mathrm{M}$ & 24 & 0 & - & 12 & 13.444 & $* * *$ & $\mathrm{P}$ \\
\hline & $\mathrm{F}$ & 0 & 2 & - & 1 & 0 & ++ & \\
\hline \multirow[t]{2}{*}{39} & $\mathrm{M}$ & 19 & 0 & - & 9.5 & 10.14 & $* *$ & $\mathrm{P}$ \\
\hline & $\mathrm{F}$ & 2 & 4 & - & 3 & 0 & ++ & \\
\hline \multirow[t]{2}{*}{41} & $\mathrm{M}$ & 7 & 0 & - & 3.5 & 2.381 & + & $\mathrm{U}$ \\
\hline & $\mathrm{F}$ & 0 & 9 & - & 4.5 & 3.6296 & + & \\
\hline \multirow[t]{2}{*}{49} & $\mathrm{M}$ & 12 & 17 & 1 & 10 & 9.3603 & $* *$ & $\mathrm{C}$ \\
\hline & $\mathrm{F}$ & 0 & 0 & 13 & 4.333333 & 12.997 & $* *$ & \\
\hline \multirow[t]{2}{*}{50} & $\mathrm{M}$ & 10 & 8 & - & 9 & 0 & ++ & $\mathrm{U}$ \\
\hline & $\mathrm{F}$ & 1 & 3 & - & 2 & 0 & ++ & \\
\hline \multirow[t]{2}{*}{51} & $\mathrm{M}$ & 2 & 0 & - & 1 & 0 & ++ & $\mathrm{U}$ \\
\hline & $\mathrm{F}$ & 0 & 2 & - & 1 & 0 & ++ & \\
\hline \multirow[t]{2}{*}{53} & $\mathrm{M}$ & 12 & 0 & - & 6 & 5.5556 & $*$ & $\mathrm{P}$ \\
\hline & $\mathrm{F}$ & 0 & 9 & - & 4.5 & 3.6296 & + & \\
\hline \multirow[t]{2}{*}{54} & $\mathrm{M}$ & 24 & 1 & - & 12.5 & 11.187 & $* * *$ & $\mathrm{P}$ \\
\hline & $\mathrm{F}$ & 2 & 13 & - & 7.5 & 3.1194 & + & \\
\hline \multirow[t]{2}{*}{57} & $\mathrm{M}$ & 1 & 22 & - & 11.5 & 9.914 & $* *$ & $\mathrm{C}$ \\
\hline & $\mathrm{F}$ & 27 & 0 & - & 13.5 & 15.432 & $* * *$ & \\
\hline \multirow[t]{2}{*}{59} & $\mathrm{M}$ & 16 & 10 & - & 13 & 0.31184 & ++ & $\mathrm{U}$ \\
\hline & $\mathrm{F}$ & 4 & 3 & - & 3.5 & 0 & ++ & \\
\hline \multirow[t]{2}{*}{60} & $\mathrm{M}$ & 0 & 44 & - & 22 & 26.727 & $* * *$ & $\mathrm{C}$ \\
\hline & $\mathrm{F}$ & 37 & 0 & - & 18.5 & 22.072 & $* * *$ & \\
\hline \multirow[t]{2}{*}{61} & $\mathrm{M}$ & 0 & 20 & - & 10 & 10.8 & $* *$ & $\mathrm{C}$ \\
\hline & $\mathrm{F}$ & 25 & 0 & - & 12.5 & 14.107 & $* * *$ & \\
\hline \multirow[t]{2}{*}{64} & $\mathrm{M}$ & 4 & 38 & 2 & 14.66667 & 26.062 & $* * *$ & $\mathrm{C}$ \\
\hline & $\mathrm{F}$ & 41 & 0 & 46 & 29 & 34.91 & $* * *$ & \\
\hline \multirow[t]{2}{*}{66} & $\mathrm{M}$ & 0 & 28 & - & 14 & 16.095 & $* * *$ & $\mathrm{C}$ \\
\hline & $\mathrm{F}$ & 32 & 0 & - & 16 & 18.75 & $* * *$ & \\
\hline
\end{tabular}


Appendix 3. Description of behaviours seen during observations of juveniles during the postfledging period.

\begin{tabular}{|c|c|}
\hline Agonistic behaviours & Description \\
\hline Chasing & $\begin{array}{l}\text { Aggressive pursuit of a conspecific or heterospecific which } \\
\text { occurs either on the ground or in flight. }\end{array}$ \\
\hline White spot display & $\begin{array}{l}\text { Exposure (ranging from partial to full) of white feathers } \\
\text { above the base of the top mandible during intraspecific and } \\
\text { interspecific interactions. Observed in both sexes. }\end{array}$ \\
\hline \multicolumn{2}{|c|}{ Food-directed behaviours } \\
\hline Eat & Consumption of food item. \\
\hline Head dipping & $\begin{array}{l}\text { Often a prelude to caching; upon reaching a cache site, } \\
\text { individuals will lower their heads several times before } \\
\text { placing the food item at the cache site. }\end{array}$ \\
\hline Caching & $\begin{array}{l}\text { The storage of food for future consumption in locations out } \\
\text { of plain sight to competitors. Visual checking, switching } \\
\text { between the left and right eye to view item, may also occur } \\
\text { prior to the cacher leaving the site. }\end{array}$ \\
\hline Cache checking & $\begin{array}{l}\text { Any visit to the cache site where the cacher visually checks, } \\
\text { but does not consume, the stored item(s). }\end{array}$ \\
\hline Cache retrieval & $\begin{array}{l}\text { The recovery and consumption of a food item(s) from a } \\
\text { cache site. This may occur within minutes to hours of the } \\
\text { item being cached. }\end{array}$ \\
\hline Re-caching & $\begin{array}{l}\text { The relocation of cached item(s) from one cache site to } \\
\text { another. Frequently observed when conspecific or } \\
\text { heterospecific competitors are perched and/or foraging near } \\
\text { the cache site (pers. obs.; Burns \& Van Horik, 2007). }\end{array}$ \\
\hline Cache pilfering & $\begin{array}{l}\text { The theft of cached item(s) by a conspecific or } \\
\text { heterospecific. Typically occurs when the pilferer has } \\
\text { observed the food item being placed at the cache site or } \\
\text { when the cacher has been observed visiting the site to check } \\
\text { on or retrieve an item (pers. obs.; Higgins \& Peter, 2002; } \\
\text { Steer \& Van Horik, 2006). }\end{array}$ \\
\hline \multicolumn{2}{|l|}{ Vocalisations } \\
\hline Singing & $\begin{array}{l}\text { A continuous vocalisation consisting of a series of phrases. } \\
\text { Often associated with territorial displays and is variable in } \\
\text { length (depends on the context). }\end{array}$ \\
\hline Chirping & A short vocalisation consisting of single notes. \\
\hline Alarm calling & $\begin{array}{l}\text { Rapid chirping which occurs when an interspecific } \\
\text { competitor and/or heterospecific predator is present. }\end{array}$ \\
\hline Begging & $\begin{array}{l}\text { Typical among juveniles and incubating females; a short } \\
\text { vocalisation which precedes or pre-empts the transfer of } \\
\text { food from an adult to the individual begging. }\end{array}$ \\
\hline \multicolumn{2}{|l|}{ Parental interactions } \\
\hline Parent feeding & $\begin{array}{l}\text { The transfer of food from the beak of a parent to that of a } \\
\text { juvenile. }\end{array}$ \\
\hline Back and forth & $\begin{array}{l}\text { Repeated transfer of food between the beak of a parent and } \\
\text { the beak of a juvenile. The interaction ends when either the } \\
\text { parent or juvenile consumes the item. }\end{array}$ \\
\hline
\end{tabular}


Appendix 4. GLMM model (Binomial distribution with logit function) investigating the factors affecting the proportion of mealworms cached by juvenile robins. Fledgling ID nested within Nest ID was included as a random factor. Asterisks (*) denote interactions between variables. $\mathrm{N}=34$ fledglings.

\begin{tabular}{lcccc}
\hline & Estimate & $\mathrm{SE}$ & $\mathrm{z}$ & $\mathrm{p}$ \\
\hline Intercept & -5.016 & 0.560 & -8.367 & $<2 \mathrm{e}-16$ \\
Fledgling age & 0.370 & 0.050 & 7.471 & $7.97 \mathrm{e}-14$ \\
Fledgling sex $^{\mathrm{a}}$ & 0.871 & 0.623 & 1.398 & 0.162 \\
Cargiver sex $^{\mathrm{a}}$ & -0.354 & 0.239 & -1.481 & 0.139 \\
DOC $^{\mathrm{b}}$ & -0.005 & 0.008 & -0.638 & 0.523 \\
FL.age*FL.sex $^{\mathrm{a}}$ & -0.057 & 0.065 & -0.878 & 0.380 \\
\hline
\end{tabular}

${ }^{a}$ Fledgling sex and Caregiver sex were categorical variables (male or female) with female as the reference level.

${ }^{\mathrm{b}}$ Duration of care was included as a continuous variable.

Appendix 5. GLMM model (Binomial distribution with logit function) of the factors affecting the proportion of cached mealworms retrieved by juveniles. Fledgling ID nested within Nest ID was included as a random factor. $\mathrm{N}=24$ fledglings.

\begin{tabular}{lcccc}
\hline & Estimate & $\mathrm{SE}$ & $\mathrm{Z}$ & $\mathrm{p}$ \\
\hline Intercept & 0.412 & 0.909 & 0.453 & 0.651 \\
Fledgling sex $^{\mathrm{a}}$ & 0.573 & 0.676 & 0.847 & 0.397 \\
Fledgling age $^{\text {Caregiver sex }}$ & 0.063 & 0.088 & 0.719 & 0.472 \\
& -0.513 & 0.663 & -0.774 & 0.439 \\
\hline
\end{tabular}

${ }^{a}$ Fledgling sex and Caregiver sex were categorical variables (male or female) with female as the reference level.

Appendix 6. GLMM model (Poisson distribution with log function) of terms proposed to affect number of sites used by fledglings when caching. Random factors included the number of mealworms cached and Fledgling ID nested within Nest ID. $\mathrm{N}=20$ fledglings.

\begin{tabular}{lcccc}
\hline & Estimate & SE & $\mathrm{z}$ & $\mathrm{p}$ \\
\hline Intercept & -0.096 & 0.597 & -0.160 & 0.873 \\
DOC $^{\mathrm{a}}$ & 0.006 & 0.006 & 0.872 & 0.383 \\
Fledgling age & 0.035 & 0.057 & 0.620 & 0.535 \\
Fledgling sex $^{\mathrm{b}}$ & -0.074 & 0.205 & -0.362 & 0.717 \\
\hline
\end{tabular}

${ }^{\mathrm{a}}$ Duration of care was included as continuous variable.

${ }^{\mathrm{b}}$ Fledgling sex was a categorical variable (male or female) with female as the reference level.

Appendix 7. LMM model (Gaussian distribution) of the factors affecting the handling time of cached items. Fledgling ID nested within Nest ID was included as a random factor. $\mathrm{N}=23$ fledglings.

\begin{tabular}{lcccc}
\hline & Estimate & $\mathrm{SE}$ & $\mathrm{t}$ & $\mathrm{p}$ \\
\hline Intercept & 1.850 & 0.106 & 17.410 & $<2 \mathrm{e}-16$ \\
Fledgling age & -0.046 & 0.009 & -5.000 & $3 \mathrm{e}-06$ \\
Caregiver sex $^{\mathrm{a}}$ & 0.093 & 0.045 & 2.030 & 0.052 \\
DOC $^{\mathrm{b}}$ & 0.002 & 0.001 & 1.776 & 0.087 \\
Fledgling sex $^{\mathrm{a}}$ & -0.024 & 0.044 & -0.543 & 0.590 \\
\hline
\end{tabular}

${ }^{a}$ Fledgling sex and Caregiver sex were categorical variables (male or female) with female as the reference level.

${ }^{\mathrm{b}}$ Duration of care was included as a continuous variable. 